\title{
A review on properties and microstructure of micro-extruded product using SPD and as-cast material
}

\author{
PINTU KUMAR* and SUDHANSU SEKHAR PANDA* \\ Department of Mechanical Engineering, Indian Institute of Technology Patna, Patna, India \\ e-mail: pintu.pme13@iitp.ac.in; sspanda@iitp.ac.in
}

MS received 20 April 2016; revised 18 March 2018; accepted 22 March 2018; published online 14 May 2018

\begin{abstract}
Micromanufacturing has wide application in the development of micro-products, but these methods are limited in developing desired properties such as dimensional tolerance, surface texture and electromechanical properties. Deformation is one of the techniques where such limitations on micro-products can be overcome based on the principle of grain refinement theory. The product developed through subtractive and additive method reveals coarse grain microstructure, whereas ultrafine grains (UFGs) are observed in the severe plastic deformation (SPD) process. Equal-channel angular pressing (ECAP) is one of the best SPD techniques to produce UFG up to a nanometre. As-cast micro-extruded product that contains coarse grains seems to be inhomogeneous, having wide deviation of physical and mechanical properties throughout its volume. ECAPbased micro-extruded product is homogeneous and has uniform physical and mechanical properties. The present review paper discusses about the influence of die geometry, die strength, specimen selection, frictional condition, temperature condition and other boundary conditions on the properties of as-cast and ECAPed extruded material. Similarly, size and direction of grain can alter the mechanical properties based on requirements and type of applications.
\end{abstract}

Keywords. As-cast material; UFG; ECAP; micro-extrusion; extrusion influencing factors; properties; microstructure.

\section{Introduction}

Manufacturing is used in industry for production of finished goods at large scale. Manufacturing has wide applications in medical, aerospace, nuclear, micro-sensors and actuator sectors. Applications of these products are limited owing to limitation of mechanical and electrical properties, shapes, sizes, microstructures, etc. Methods and processes involved in products manufacturing need to be considered for enhancement of its limitation and use. At present, advancement of technology due to size miniaturization is in high demand. To miniaturize the size of demanding products, manufacturing industries work for the production of small-scale components while researchers focus on improvement of its mechanical properties. Improved methodology, hybrid manufacturing technology, process optimization to reduce the complexity of the processes, system, design, cost, energy, pollution and health hazard are a few considerations of researcher's studies.

Various micro-products as given in table 1 are produced from several micromanufacturing systems, which require less space and low power consumption [1-14]. Micromanufacturing is categorized into micro-electrical-

*For correspondence mechanical-system (MEMS) and non-MEMS. Some micromanufacturing methods are subtractive, additive, forming, joining and hybrid processes as listed in table 2 [15]. These methods work on the principle of mechanical forces, thermal, dissolution, ablation, re-composition, solidification, polymerization/lamination and sintering as given in table $3[16,17]$. Laser ablation and anisotropic etching of silicon is a new method to fabricate an extrusion die having $10-\mu \mathrm{m}$ die surface roughness. Photochemical is another method to get 2- $\mu \mathrm{m}$ surface roughness of extrusion die. Micro-machining, micro-forming and advanced lithography are some reported micromanufacturing methods to produce micro-reactors, fuel cells, micro-medical components and micro-mechanical devices. Micro-forming is one of them to get a close tolerance limit and improved properties as compared with other manufacturing processes.

Different shapes and sizes of products with improved mechanical and electrical properties are achieved through deformation processes. Several factors such as die design, load, temperature, friction condition and size effects affect the deformation behaviour (hardness, flow stress, residual stress, microstructure, ductility, strength, etc.). For an understanding of deformation behaviour with change in grain and scale size, systematic research investigation has been conducted for micro-extrusion using as-cast and grain- 
Table 1. List of micro-parts fabricated by micro-extrusion.

\begin{tabular}{lccc}
\hline Materials & $\begin{array}{c}\text { Micro- } \\
\text { products }\end{array}$ & Applications & Reference \\
\hline $\begin{array}{l}\text { LaAlNi } \\
\text { amorphous }\end{array}$ & Gear & MEMS & {$[2]$} \\
$\quad$ alloy & & & \\
AZ31 alloy & & & {$[3]$} \\
$\mathrm{Cu}-\mathrm{Zn}$ & Pin & IC carriers, fasteners, & {$[4]$} \\
$\mathrm{Cu}, \mathrm{Cu}-$ & & micro-screws, sockets & {$[5-7]$} \\
$\mathrm{C} 11000$ & & & \\
$\mathrm{CuZn30}$ & & & {$[4,8]$} \\
$\mathrm{CuZn15}$ & Double & Micro-condenser tube & {$[9,10]$} \\
$\mathrm{Pure} \mathrm{Al}$ & cup & & {$[11,12]$} \\
$\mathrm{Cu}$ & & & {$[13]$} \\
$\mathrm{A} 1100$, & & & {$[14]$} \\
$\mathrm{A} 3003$ & & & \\
\hline
\end{tabular}

refined material. This review paper discussed about the principle of micro-extrusion, micro-product fabrication using as-cast and grain-refined material, affecting parameters on deformation behaviour and properties of micro-product, a conclusion, and application.

\subsection{Micro-forming}

To better understand the product application and the method of fabrications authors has systematically done a review of product application and their limitation which help the investigators to know the effects of micro-forming due to change of material, process, tooling and machine tool. Product properties, manufactured in large scale are not similar to product properties produced in small scale, even using the same processes and these changes are due to size effect [18, 19]. In micro-forming size effect is related to scale size as well as number of grain present during forming processes. In order to achieve ultrafine grains (UFGs), severe plastic deformation (SPD) technique is used [20]. Parts produced through SPD have high strength to weight ratio, long life and good mechanical properties as compared with coarse grain (CG) material and the grain size changes from micrometre to nanometre range [20]. Segal proposed ECAP as one of the most promising techniques of SPD to

Table 2. Type of manufacturing technology for micro-product [15].

\begin{tabular}{|c|c|}
\hline Processes & Method \\
\hline Subtractive & $\begin{array}{l}\text { Micro-mechanical cutting: turning, milling, grinding, polishing } \\
\text { Micro-ECM, micro-EDM, electro-beam-machining, laser-beam-machining, photo-chemical-machining }\end{array}$ \\
\hline Additive & $\begin{array}{c}\text { Direct writing: ink-jet, laser-guided } \\
\text { Surface coating: CVD, PVD } \\
\text { Micro-injection moulding, micro-casting, photo-electro-forming, sintering, polymer deposition, chemical deposition, } \\
\text { stereo-lithography }\end{array}$ \\
\hline Deforming & $\begin{array}{c}\text { Micro-forming: extrusion, forging, stamping, deep drawing, bending, super-plastic forming, incremental forming, hydro- } \\
\text { forming, } \\
\text { hot embossing }\end{array}$ \\
\hline Joining & Vacuum soldering, micro-mechanical assembly, laser welding, laser, resistance, bonding, gluing \\
\hline Hybrid & $\begin{array}{l}\text { LIGA, LIGA combined with laser machining, micro-laser ECM, micro-EDM and laser assembly, micro-assembly injection } \\
\text { moulding, combined micro-machining and casting }\end{array}$ \\
\hline
\end{tabular}

Table 3. Working principle of manufacturing method [17].

\begin{tabular}{|c|c|c|}
\hline Working principle & Processing & Method \\
\hline \multirow[t]{3}{*}{ Mechanical force } & Joining, & Ultrasound, cold pressure welding \\
\hline & Mass containing & Rolling, deep drawing, forging, punching \\
\hline & Subtractive & Cutting, grinding, blasting, ultrasonic machining \\
\hline \multirow[t]{3}{*}{ Thermal effect } & Subtractive & EDM, LBM, EBM \\
\hline & Joining & Welding (resistance, laser), soldering (resistance, laser, vacuum), bonding \\
\hline & Additive & CVD, PVD \\
\hline Ablation & Subtractive & LBM (excimer, short pulse) \\
\hline Dissolution & Subtractive & ECM, relative ion etching, isotropic and anisotropic etching \\
\hline Solidification & Mass containing & Injection moulding, casting \\
\hline Re-composition & Additive & Electroforming, chemical deposition \\
\hline \multirow[t]{2}{*}{ Polymerization/lamination } & Joining, & Gluing \\
\hline & Additive & Stereo-lithography, photo-forming, polymer deposition \\
\hline Sintering & Mass containing & Combination of mechanical and thermal principles \\
\hline
\end{tabular}


produce UFG by shear phenomena by introducing large plastic strain without change in initial dimension of the sample [21]. In the micro-forming process die design, its fabrication and selection are more effective to reduce overall manufacturing cost and get a desire product. Regular use of the die may harm its design with imposing wear, friction, corrosion, thermal effect and high stresses causing deterioration. Die damage can be minimized using a preheated sample and preheated die or by using different types of lubricants available in liquid, solid or spray form to nullify the friction and enhance the product properties and desired life of die [22].

\section{As-cast material}

The method of casting started in $500 \mathrm{BC}$, when people used this method to manufacture simple weapons or other parts without any complexity [23]. Casting in solidification is the process where substrate at outer and near liquid-solid region nucleates in a way to involve a different phase, but in a nonferrous alloy these three regions do not appear simultaneously [24]. In sand mould casting, liquid zone disappears quite early before solidification and a fully solid zone appears at the end of solidification. The material after solidification forms different sizes of microstructure, from which material properties can be evaluated. CG microstructure formed through casting is in the range of sub-millimetre to sub-micrometre. Control of grain size depends upon type of constituents, percentage of constituents, pouring pattern, pouring time and time for solidification and gasification (removing processes of impurities from molten metal in slag form) [25]. Solidified grains possess three different regions-chill region, columnar region and equi-axed region as shown in figure 1 .

Chill region in nucleation shape is near the part of mould cylinder where more heat is transferred to the surrounding. Columnar region is an anisotropic region, which is long and has equal properties in all directions, whereas equi-axed region is isotropic in nature (uniform in all orientations) and takes more time during solidification. The Hall-Pitch relation is used to know grain size $(d)$ as a function of yield

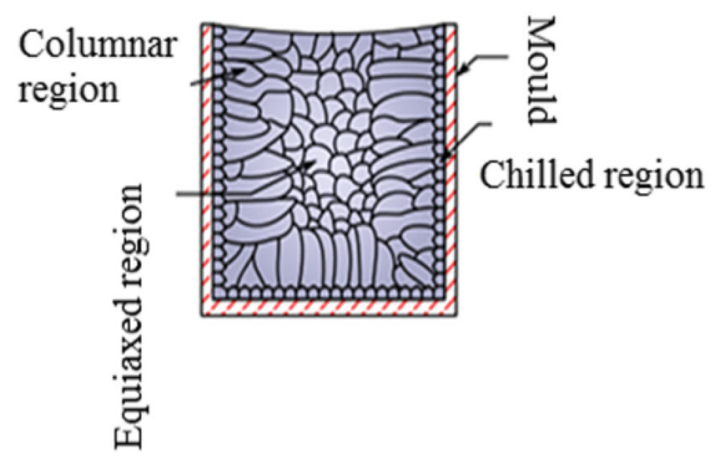

Figure 1. Different regions of formed microstructure [25]. strength $(\sigma)$, through which change of material ductility can be derived from Eq. (1) [26]. After deformation, larger grains pile up into a number of dislocations, leading to higher driving force to move the dislocation and hence yield strength due to such refinement increases. Properties of cast material change on changing casting parameters and solidification time; hence obtaining an as-cast material with desired properties is a challenging task.

$$
\sigma=\sigma_{0}+\frac{k}{\sqrt{d}}
$$

where $k$ and $\sigma_{0}$ are material constants.

\subsection{Effect of casting parameter on properties of cast}

The possibility of high-strength material deformation in micro-extrusion is very tough and it can fail the die. Hence the selected material should have high ductility to get deformed and form a high-strength product. An attempt has been made to understand the effects of chemical composition, temperature and pressure condition on ductility, strength and microstructure of materials. The fine microstructure of all-cast Al alloy is due to lowering of die temperature, resulting in high degree of under-cooling, which changes the crystal direction opposite to heat removal direction as shown in figure 2 [27]. Strength of materials in low-pressure die casting increases with fast cooling [28]. A defect-free microstructure of $\mathrm{Al}-\mathrm{Si}$ in green sand casting is observed at low pouring temperature [29].

Ductility of cast Al alloy increases with increasing casting pressure but sharp needle grains present in the injection casting as shown in figure $3 \mathrm{a}$ and $\mathrm{b}$ oppose the material ductility [30]. Increase in pressure reduces grain size and increases heat transfer rate; hence, yield strength and ductility of material increase in a squeeze casting of $\mathrm{Al}$ alloy [31, 32]. Injection pressure die casting also improves the mechanical properties such as hardness, yield strength, tensile strength and grain refinement of A1350 [33].

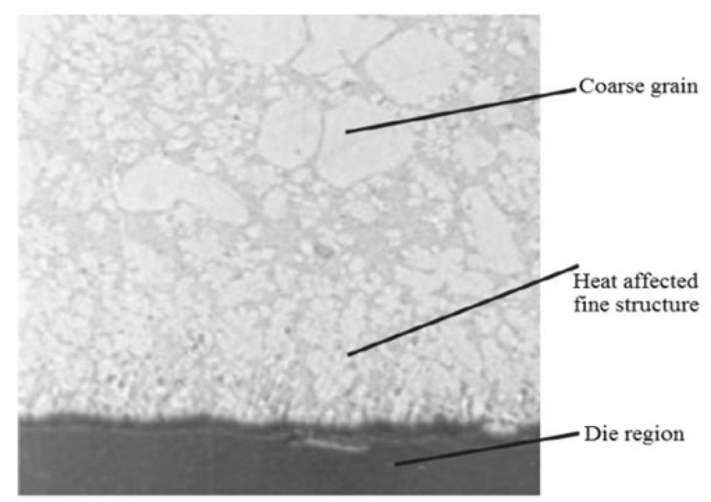

Figure 2. Heat-affected microstructure [27]. 

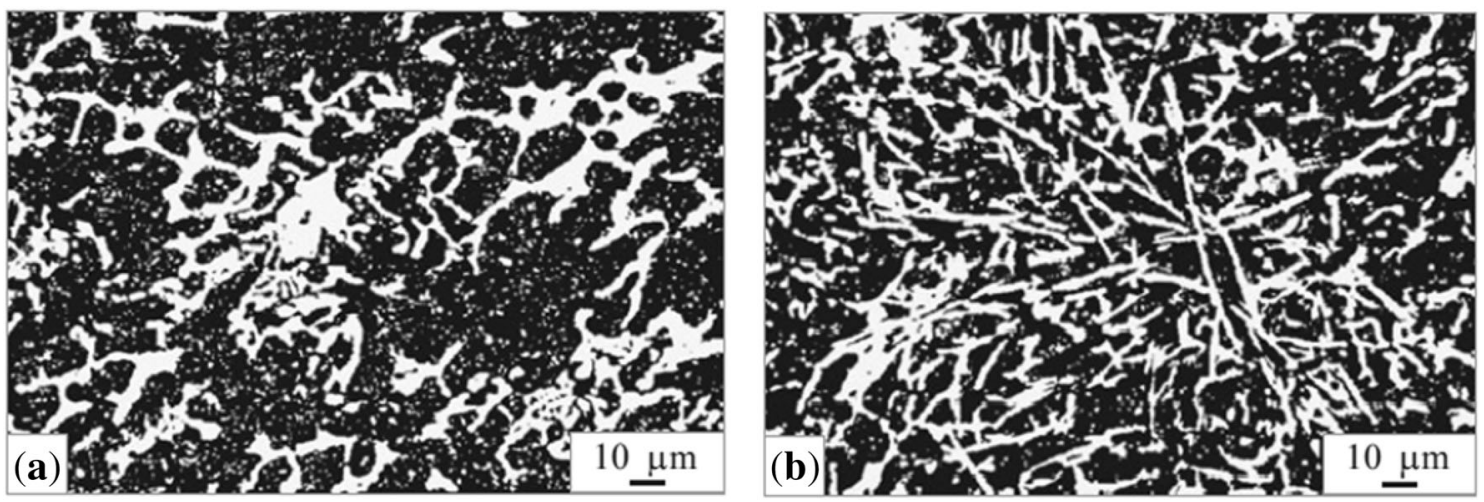

Figure 3. Casted microstructure: (a) casting with pressure crystallization and (b) injection casting [30].

Mechanical properties of cast Al-Si alloy achieved through low-pressure die casting has superior mechanical properties in comparison to sand casting, gravity die casting and high pressure die casting [34]. According to researchers [35, 36] molten metal takes more time in filling the mould cavity in a low-pressure die casting, resulting in CGs, which leads to lower yield strength and tensile strength of AM50 alloy.

$\mathrm{Al}$ alloys grain refinement has been classified into nucleate paradigm (heterogeneous) and solute paradigm [37]. In solute paradigm, affected dendrites formed in cooled zones generate new grains, but grain growth is restricted by high-strength element (Ti) [38]. They proposed a growth restricting factor (GRF) of new grains as given in Eq. (2), where $m_{i}$ is the liquidus gradient, $C_{0}$ is the bulk composition and $k_{i}$ is the partition coefficient between solid and liquid. In the presence of a number of solutes in the melt, GRF is added to avoid the interaction of solutes. Powerful isolation by GRF with effective cooling starts nucleation. They correlate the average grain size with GRF for different alloying elements as shown in figure 4 and concluded that with the addition of \% of Ti in the LM alloy, GRF decreases. Increase in Ti percentage in an Al-Ti alloy produces refined grains [39], resulting in increase of yield stress [40] in a high-pressure die casting. Addition of iron

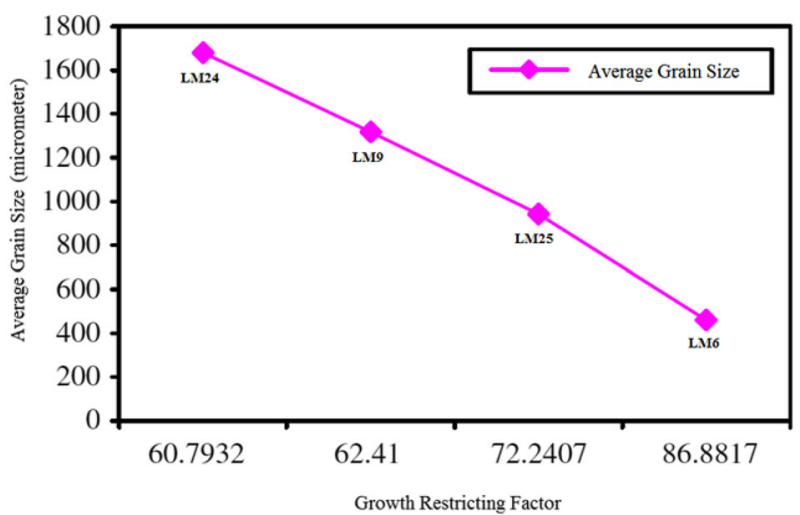

Figure 4. Average grain size w.r.t. GRF for aluminium LM alloy [38]. in the $\mathrm{Al}-\mathrm{Mg} 2-\mathrm{Si}$-based alloy reduces grain size, thus increasing the yield strength, tensile strength and hardness of the cast [41].

$$
\mathrm{GRF}=\sum m_{i} C_{0}\left(k_{i}-1\right) .
$$

A few reported compositions show that the material is ductile in nature while in some cases it becomes harder due to high pressure or different solidification rates. Hence, changing the chemical composition, selection of casting method and control of casting parameter can determine the ways in which mechanical properties change.

\section{UFG refined materials}

UFG materials are used to manufacture parts that have high strength, high ductility, low friction coefficient, good wear resistivity and good corrosion resistance by imposing ultralarge plastic strain. The parts manufactured through UFG have high strength to weight ratio. CG material under SPD technique is transferred to UFG material. There are several SPD techniques available such as ECAP [21], repetitive corrugation and straightening (RCS) [42], accumulative roll bending (ARB) [43], high-pressure torsion (HPT) [44], cyclic extrusion compression (CEC) [45], severe torsion straining (STS) [46], constraint groove pressing (CGP) [47] and cyclic closed die forging (CCDF) [48].

Segal [49] used ECAP processes to achieve UFG of the material. Square or round billets are extruded without changing their initial dimension. In die design, an L-shape channel is bent at an abrupt angle known as channel angle $(\phi)$ (lies between $0^{\circ}$ and $180^{\circ}$ ) and corner angle $(\psi)$ (varies from $0^{\circ}$ to $20^{\circ}$ ). The corner angle makes an arc with channel angle as shown in figure 5 [21]. Corner angle and channel angle at the bend enable the billet to move forward by plane shearing. The relation used for maximum equivalent strain $(\varepsilon)$ in each number of passes $(N)$ is given in Eq. (3) [21]. Rise of equivalent strain further increases with 


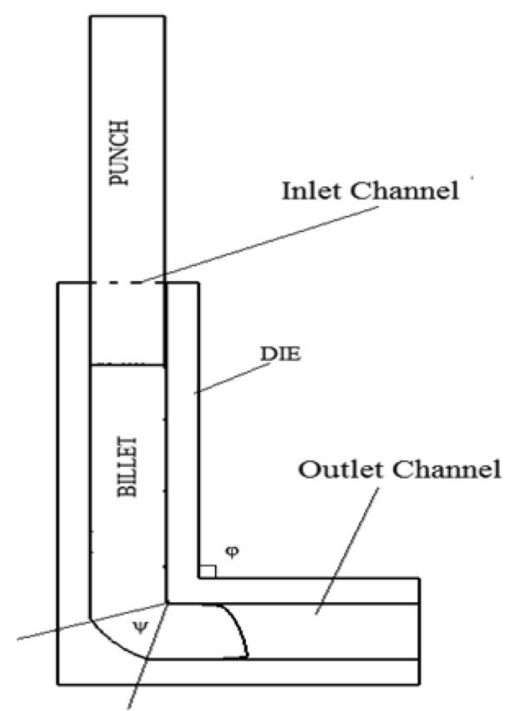

Figure 5. Representation of ECAP channel.

increase in the number of passes. The maximum equivalent strain distribution in L-shape ECAP channel for a single pass at $90^{\circ}$ channel angles and $0^{\circ}$ corner angles is 1.15 .

$$
\varepsilon=\frac{N}{\sqrt{3}}\left\{2 \cot \left(\frac{\phi+\psi}{2}\right)+\psi \operatorname{cosec}\left(\frac{\phi+\psi}{2}\right)\right\} .
$$

Equivalent strain distribution in L-shape ECAP channel increased two times or more with multiple passes $(N)$ depending upon the type of material. The method of using extruded material is followed by four different routes with three different angles of rotation along its longitudinal directions. In route $A$, the billet is repressed without rotating in any direction. In route $\mathrm{B}_{\mathrm{A}}$ the billet is rotated by $90^{\circ}$ either in a clockwise or in anticlockwise but in the next pass, rotation is continued to reverse the previous rotation. In route $\mathrm{B}_{\mathrm{C}}$ the billet is rotated by $90^{\circ}$ along longitudinal direction either clockwise or anticlockwise and rotation in the next pass is continued following the previous rotation. Grain refinement in route $B_{c}$ is much better than in other routes. In route $C$ any of the direction is valid when the sample is rotated by $180^{\circ}$ for each pass. Shapes of shear planes through different angles of rotation is shown in figure 6 [50].

\subsection{Changes in material property with ECAP processes}

Grain size of pure $\mathrm{Cu}$ annealed at $600^{\circ} \mathrm{C}$ for $2 \mathrm{~h}$ reduced from $60 \mu \mathrm{m}$ to $250 \mathrm{~nm}$ in a total of 8 passes through route $\mathrm{B}_{\mathrm{c}}$ as shown in figure 7a and $\mathrm{b}$ [51]. It can be observed from figure 7 that further increase in the number of passes beyond 8 does not change the grain size. Flow pattern of P31664 with grain-refined material after two passes when

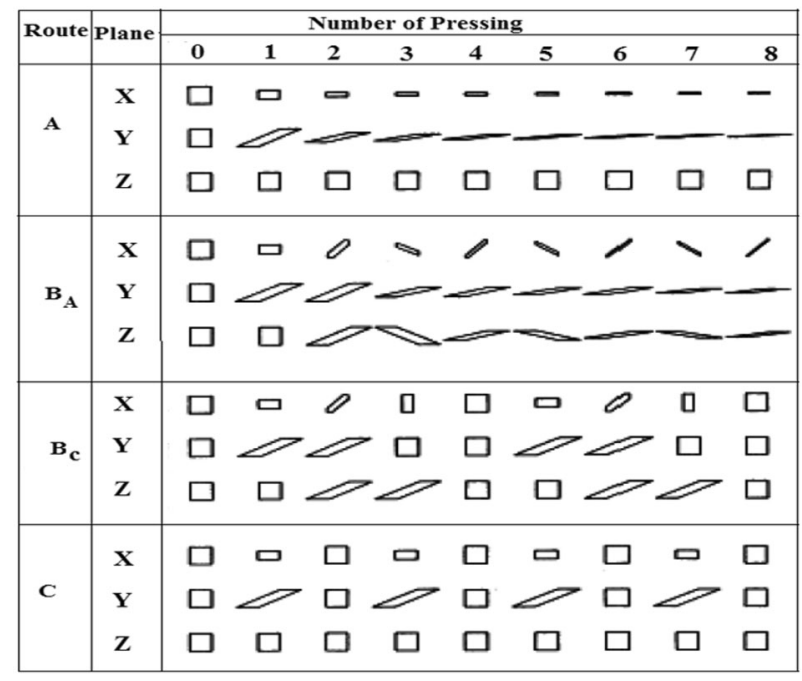

Figure 6. Schematic deformation of plane in each route [50].

rotated through routes $\mathrm{A}$ and $\mathrm{C}$ at $350^{\circ} \mathrm{C}$ by $90^{\circ}$ channel angle is shown in figure $8 \mathrm{a}$ and $\mathrm{b}$, where further grain refinement of material in route $\mathrm{C}$ is possible [52]. The study of pre-extruded AZ31 extruded alloy at $350^{\circ} \mathrm{C}$ is used to pass through ECAP channel at $180^{\circ} \mathrm{C}$ followed by route $\mathrm{B}_{\mathrm{c}}$ [53] and it is found that microstructure that remained unchanged up to 4 passes is completely refined after 12 passes. Change of microstructure also shows that the yield stress increases up to 2 passes and decreases thereafter.

AZ31 with low-angle grain boundary (LAGB) has been studied by researchers and they observed that low misorientation angle $\left(5^{\circ}-10^{\circ}\right)$ imposes high strain hardness, resulting in fine grains [54]. LAGB of Al-5052 changes drastically to high-angle grain boundary (increase in misorientation angle) with an increase in temperature, resulting in larger grain size as shown in figure 9 [55]. During ECAP of Al-6061 alloy at high strain rates, friction decreases the material density as well as porosity, resulting in increase of ductility of around $16 \%$ and toughness of about $12.6 \%$ with almost constant yield strength [56]. The increase in ductility and toughness of the billet is due to the backpressure produced by the lubricants. However, McKenzie and Lapovok [57] observed enhanced ductility, but reduced yield strength for A16016 by employing backpressure of $200 \mathrm{MPa}$. In another work, Xu and Langdon [58] observed that homogeneity increases with increasing number of passes, thus increasing hardness of material.

\section{Micro-extrusion}

Extrusion is a process to give desired shape and size when the sample is allowed to pass through a fixed cross-sectional area at constant or varying load condition. It is classified as forward, backward and hydrostatic extrusion 

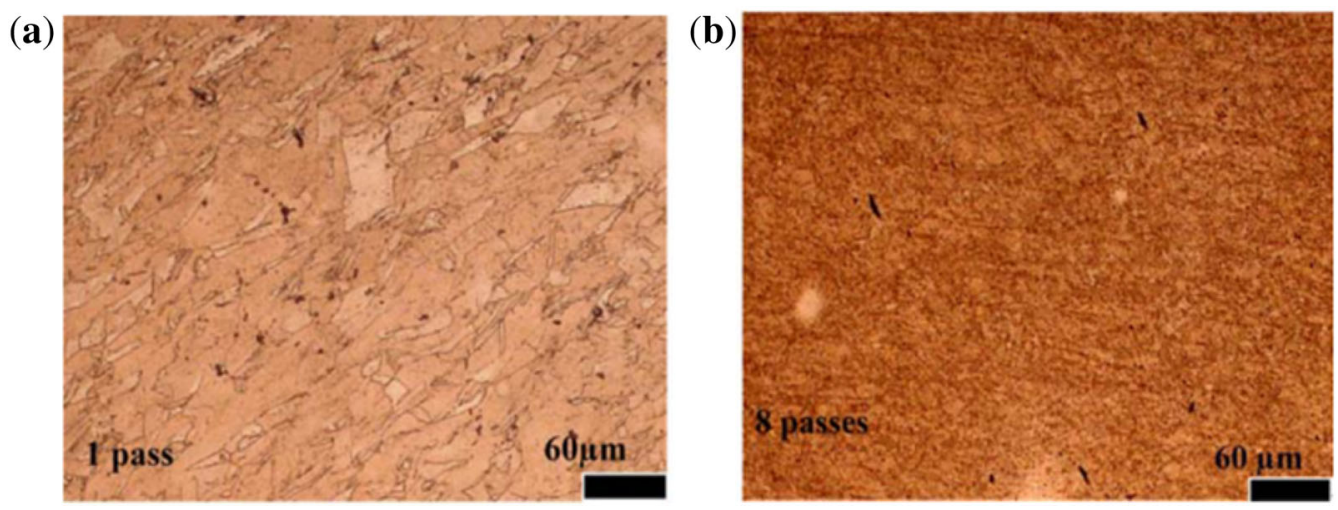

Figure 7. Longitudinal flow of $\mathrm{Cu}$ microstructure (a) after 1 pass and (b) after 8 passes [51].

(a)

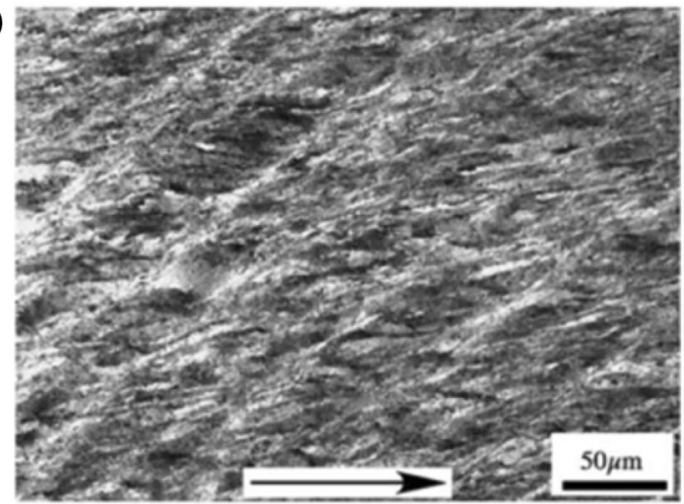

(b)

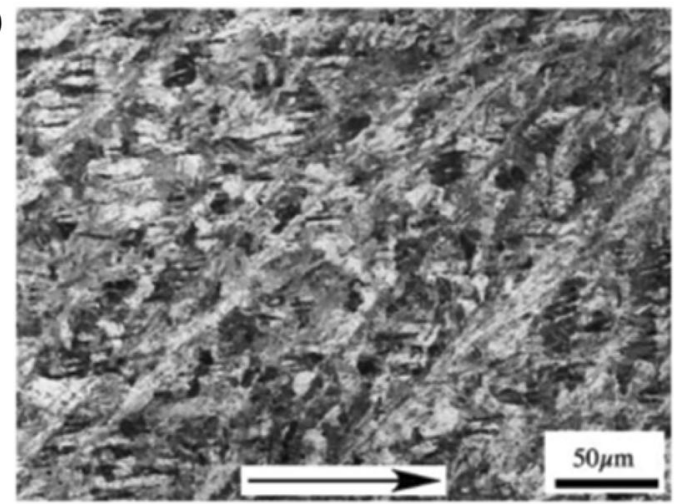

Figure 8. Microstructure after two passes of P31664: (a) route A and (b) route C [52].

[59] as shown in figure 10. In micro-extrusion, any two dimensions of fabricated parts lie below 1-mm range [19]. In a micro-extrusion process, die design depends on die material, die strength, die chamfer, dead zone, die complexity, die symmetry, die wall thickness, die weight and tolerance. Plain carbon steel (PCS) dies require lower extrusion pressure as compared with tool steel (TS) die, but the surface finish of extruded sample is better in case of TS die in extruding $\mathrm{Cu}-\mathrm{Zn}$ alloy [60]. Miniaturization of die outlet hinders the flow of sample; hence lubrication is necessary for smooth flow [61]. This paper focuses on micro-extrusion technique to know variation of properties and microstructure of as-cast and ECAP-based material.

\subsection{Factors influences extrusion properties}

Extrusion parameters such as size effect, die geometry, die strength, specimen selection, frictional condition, temperature condition and other boundary conditions affect the properties and quality of extruded products. Hence the present aim is to collect a list of parameters that affect the properties and quality of product investigated by several researchers. 4.1a Die effect: Dies with high surface finish and very good mechanical properties are used to protect it from wear and stress concentration [62] in micro-forming operation. Design and selection of material for manufacturing a die is based on power to withstand high stress and thermal shock,

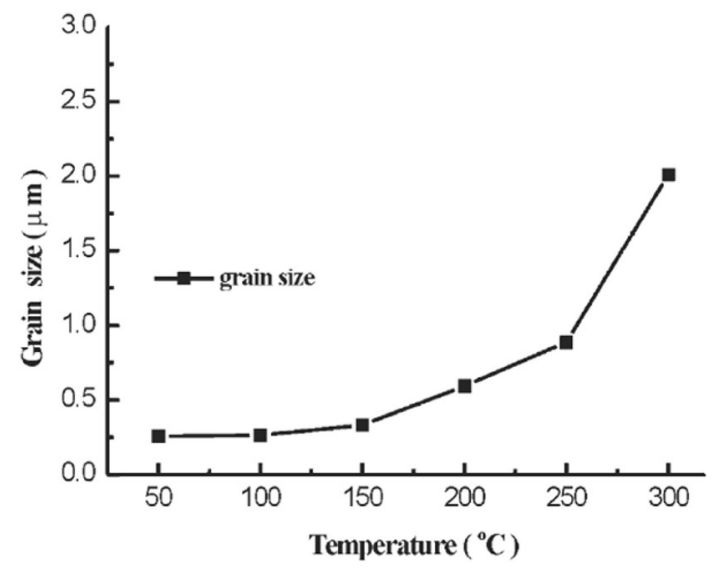

Figure 9. Increment of low-angle boundary with increasing temperature [55]. 

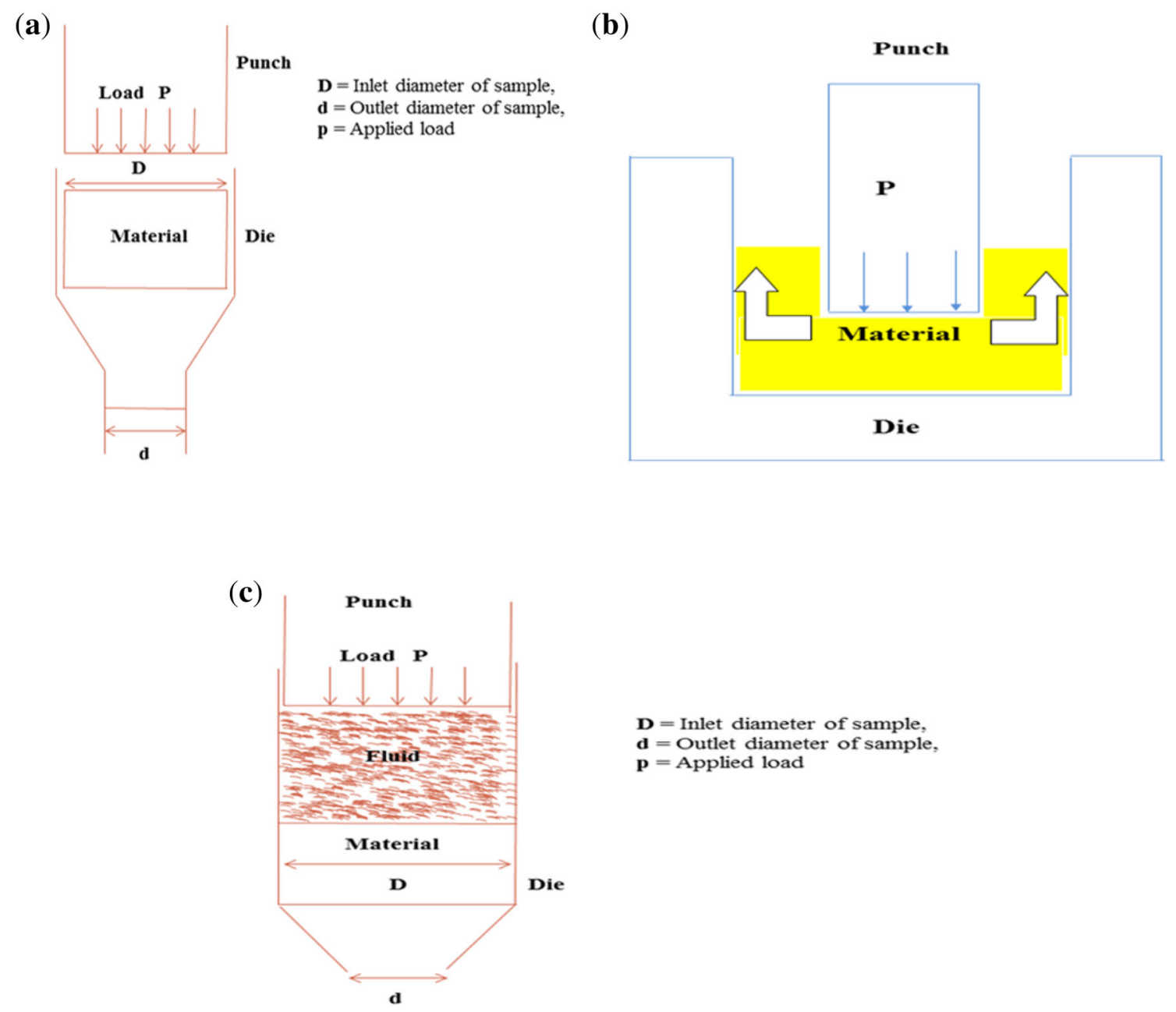

Figure 10. Schematic of extrusion: (a) forward, (b) backward (c) hydrostatic [59].

and resistance to oxidation. Adeosun et al [63] observed that extrusion pressure required to extrude Al-6063 alloy increases with increase in die angle for both TS and PCS dies, whereas extrusion pressure required for TS die is more as compared with PCS die at lower die angle as shown in figure 11a-d. At lower die angle, maximum elongation of Al-6063 is observed in case of TS die shown in figure 11e. Similarly hardness of extruded sample increases with increase in die angle and hardness of extruded sample is higher in a TS die as compared with PCS die shown in figure 11f.

4.1b Effect of ultrasonic vibration: In micro-extrusion, vibration has been applied to enhance formability and surface roughness of a product. Use of ultrasonic vibration in extrusion of Al-1100 is employed to reduce the flow stress and coefficient of friction between the die-workpiece surfaces as shown in figure 12a and $b$ [12]. Bunget and Ngaile [12], during their work in micro-forward extrusion and double cup extrusion, observed that microgap between the die and workpieces constantly decreases, resulting in decrease of extrusion load and surface roughness as shown in figure $12 \mathrm{a}$ and $\mathrm{b}$. Figure 12a also shows that Lubsol W-72 SK lubricant with ultrasonic vibration achieves $18 \%$ lower punch load than that without ultrasonic vibration. Higher punch load reduction is achieved using Lubsol W-72 SK lubricant (18\%) than polymeric lubricant (16\%) and Dailube DR-38 lubricant $(12 \%)$.

4.1c Size effect: There are two types of size effect: first one is a grain size effect, which is shown in figure 13a, and the second is feature size effect or a scale effect as shown in figure 13b [64, 65]. Changing the size of grain at constant scale is termed as grain size effect. It is further categorized into density effect, shape effect and microstructure effect [66]. In scale effect, scale changes but the grain size remains constant. Inconsistent deformation behaviour is observed when scale changes from conventional to microlevel; such inconsistency is based on material strengthening, increase in interfacial friction and microstructure evolution [67]. 


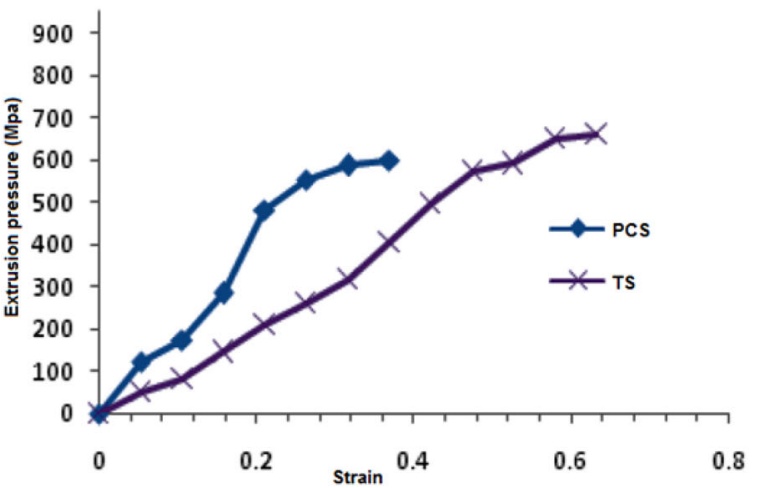

(a) $15^{0}$

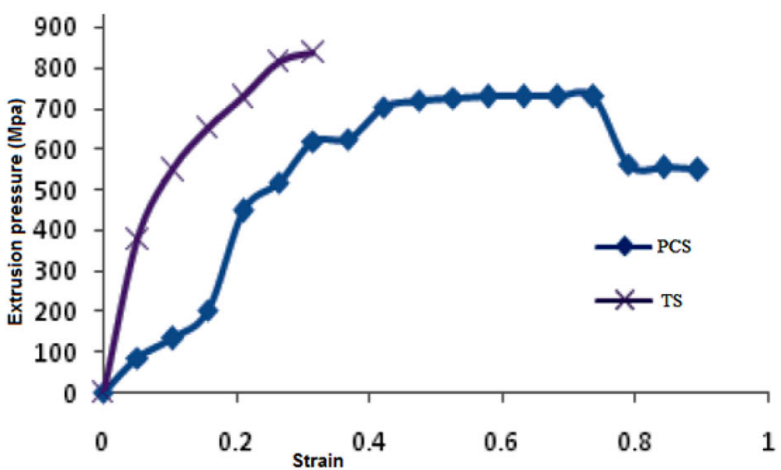

(c) $45^{0}$

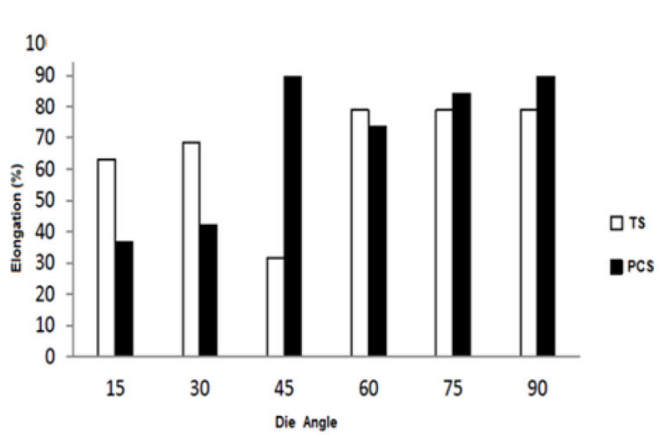

(e)

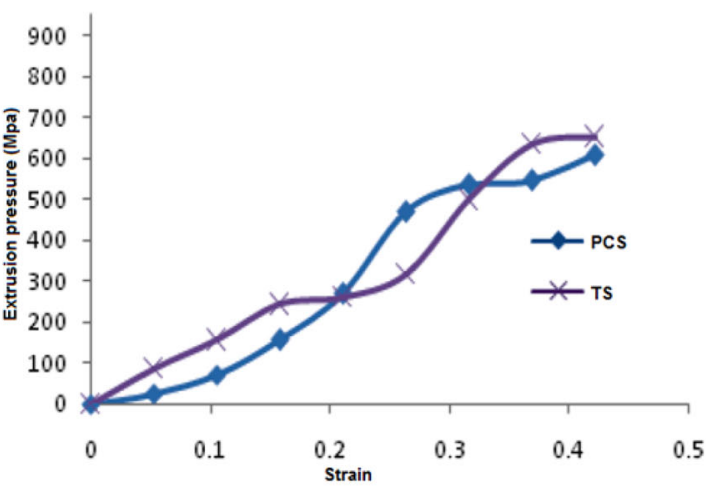

(b) $30^{0}$

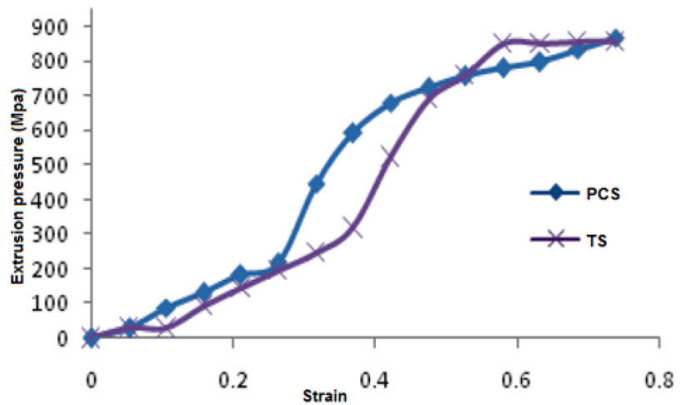

(d) $60^{\circ}$

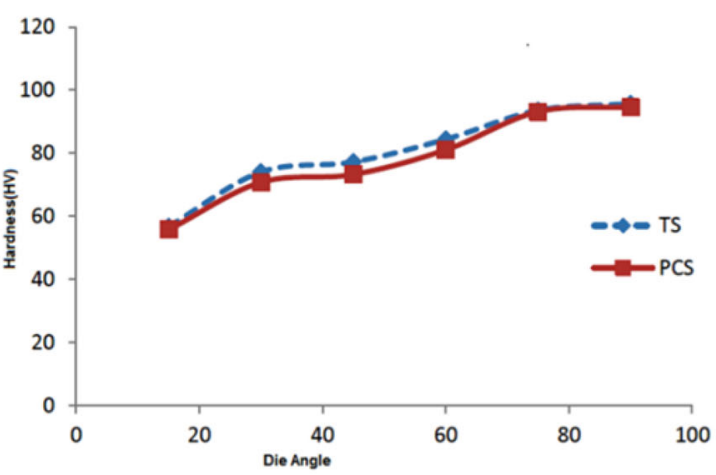

(f)

Figure 11. Effects of die entry angle on extrusion pressure at (a) $15^{\circ}$, (b) $30^{\circ}$, (c) $45^{\circ}$ and (d) $60^{\circ}$, (e) on percentage elongation of billet from TS and PCS dies and (f) on hardness [63].

4.1d Material thickness effects: In micro-scale, a fixed aspect ratio thickness of sample plays an important role in determining the deformation behaviour. Flow stress-strain relation (swift model) of $\mathrm{C} 1200$ materials as shown in figure $14 \mathrm{a}$ and $\mathrm{b}$ is a function of thickness $(t)$ and grain size $(g)$ as given in Eq. (4) [68]. Considering the effect of thickness and grain size, flow stress $\left(\sigma_{\mathrm{f}}\right)$ of the developed swift model also depends on the initial yield strain $\left(\varepsilon_{\mathrm{o}}\right)$, equivalent strain $(\varepsilon)$, strength coefficient $\left(K_{\mathrm{o}}\right)$ and strainhardening exponent $(n)$ where $a-e$ are extended material parameters obtained using the Nelder-Mead method. From
Eq. (4) it is observed that increase of grain size as well as decrease in thickness is caused for lower flow stress. Yeh et al [68] observed increase in flow stress with decrease in grain size for a constant thickness. Similarly, they concluded that flow stress decreases with decreasing thickness of specimen for a constant grain size. With decreasing thickness of a copper specimen, number of grains decreases, resulting in increase of surface roughness, which leads to fracture strain [69].

$$
\sigma_{\mathrm{f}}=k_{\mathrm{o}}\left(\varepsilon+\varepsilon_{\mathrm{o}}\right)^{n} f(g, t),
$$



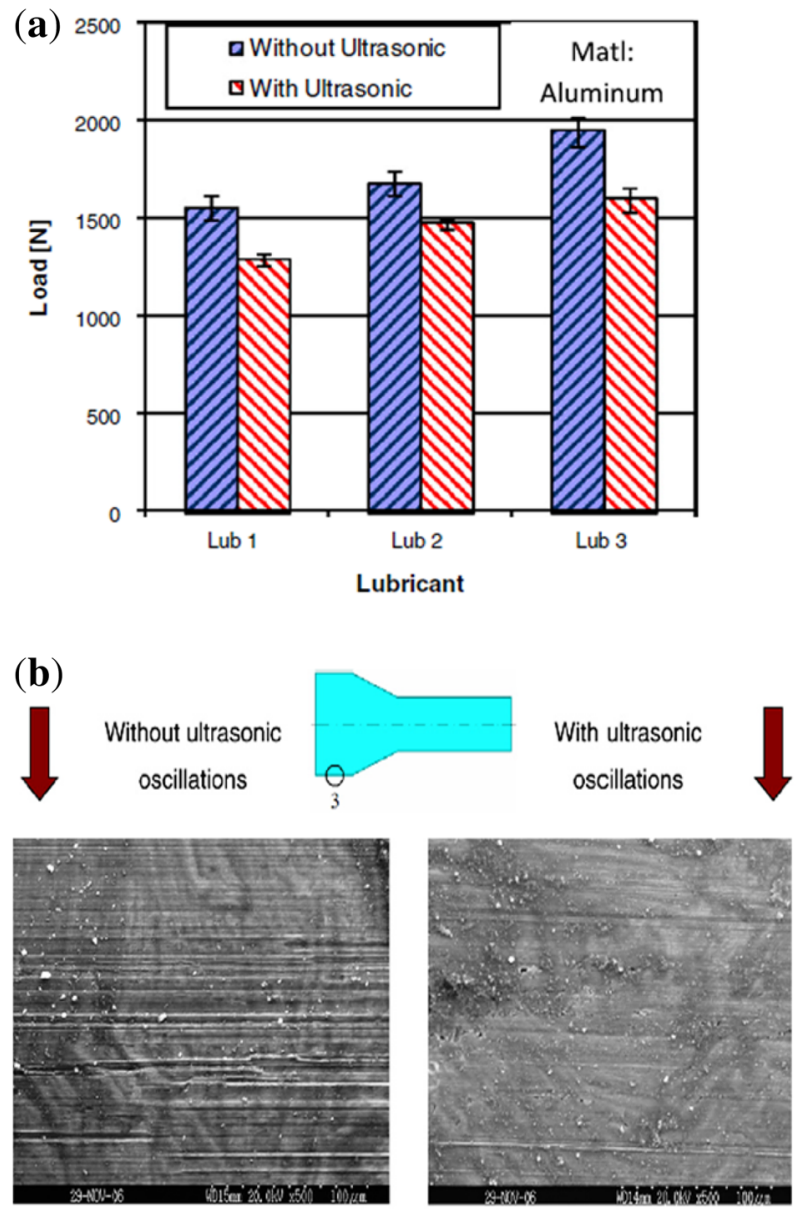

Figure 12. Extrusion of Al-1100 with and without vibration: (a) load variation and (b) surface finishing [12].
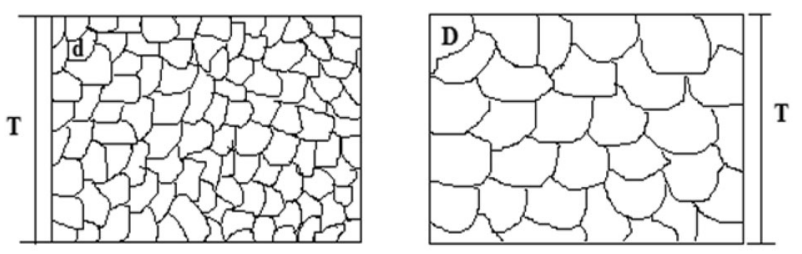

(a) Grain size effect
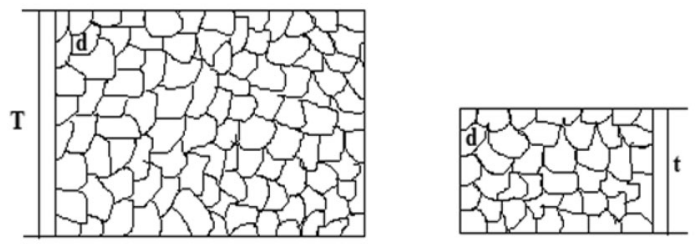

(b) Feature size effect

Figure 13. Schematic of size effects: (a) grain size effects and (b) feature size effects [64].

$$
f(g, t)=\frac{a t^{2}+b t+c}{d g+e} .
$$

4.1e Friction effect: Lubricants are used to minimize friction between a die and workpiece, which reduces required load in deformation of materials. Reduction of frictional factor depends on type of lubricant used, geometry of workpiece and die, and working condition. Friction factor depends on type of lubricant, i.e., solid, liquid or dried as well as its constituent [70]. Based on a mechanical-theoretical model, friction factor is recognized as open and closed lubricant types. Friction reduces when a low-viscosity mineral oil is added to a soap during cold forming of steel [71]. Refined palm oil in extrusion reduces the load as compared with additive-free paraffinic mineral oil with an improved surface finish [72]. Syahrullail et al [72] also observed that increasing thickness of lubricant over a sample reduces metal to metal contact, resulting in increase of sliding velocity. In the extrusion of annealed 21B3 steel, coefficient of friction with vegetable oil (VO) is comparatively higher as compared with other lubricants (cutting oil (CO), no lubricant (DRY), extreme pressure oil (EPO) with sulphur additives and new additive pressure oil (NEPO)) as shown in figure 15 [73]. Friction coefficient can be minimized by choosing the type of lubrication but the effect of lubrication is nullified with increasing pressure and increasing temperature. Hence, a further study is required to test with other types of lubricants available in the market at different extrusion conditions.

Engel [9] determined that an open lubricant can have two major causes for a friction effect in which share of open lubricant packet as well as friction factor increases with reduced specimen size, while in case of a close lubricant, packet stress acting on the roughness peaks is reduced by hydrostatic pressure developed in the close lubricant packet region. During the extrusion, as the modified Tabor model shows, coefficient of friction $(\mu)$ is a function of friction factor $(f)$, strain hardening constant $(n)$ and contact area ratio $(\alpha)$ as given in Eq. (5) [74]. This equation is useful to predict $\mu$ for different sizes of grain during the process of miniaturization. Based on Coulomb and constant shear stress two different laws for friction condition given in Eqs. (6) and (7) are used to know the impact of stress and deformation behaviour in elastic and plastic ranges [75]. Due to size effect, variation of surface waviness in the elastic and plastic regions may result in different frictional stresses $\left(\tau_{f}\right)$ and hence a rise of punch load can be predicted, where $F_{\mathrm{f}}$ is the frictional force, $F_{\mathrm{n}}$ is the normal force, $\sigma$ is the normal stress, $A$ is the contact area, $f_{\mathrm{s}}$ is the frictional shear factor $(0-1)$ and $K_{\mathrm{s}}$ is the shear yield strength. Eqs. (6)-(8) will help build proper die design configuration to sustain load during deformation. During micro-extrusion, Piwnik and Mogielnicki [75] also observed that with decrease in roughness of specimen, frequency of surface waviness fluctuation increases, resulting in friction coefficient increases as given in Eq. (8) but high wave frequency fluctuation with increasing extrusion pressure is not true for conventional scale. 
(a)

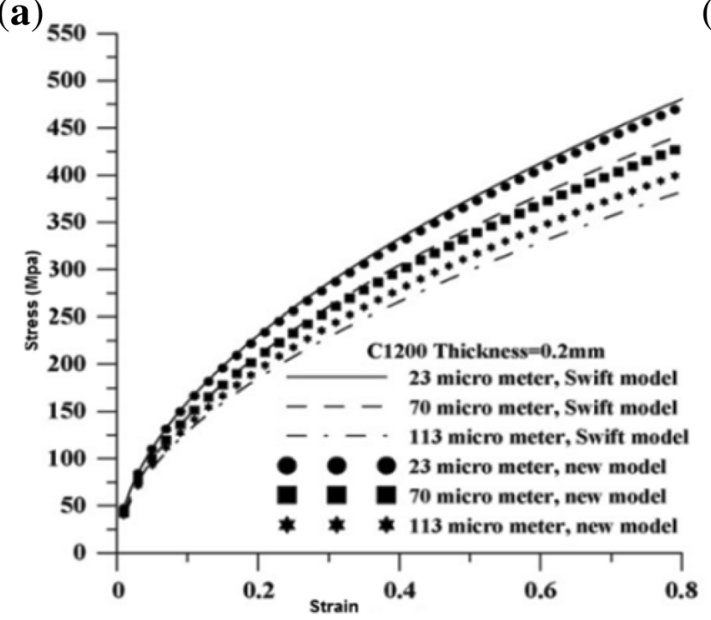

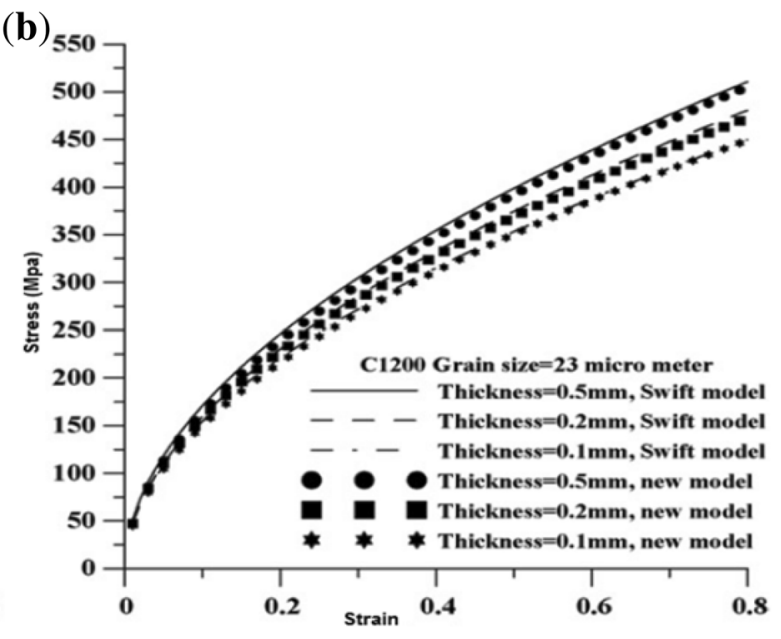

Figure 14. Stress and strain curve for (a) various grain sizes at constant thickness of $0.2 \mathrm{~mm}$ and (b) various thicknesses at constant grain size of $23 \mu \mathrm{m}$ [68].

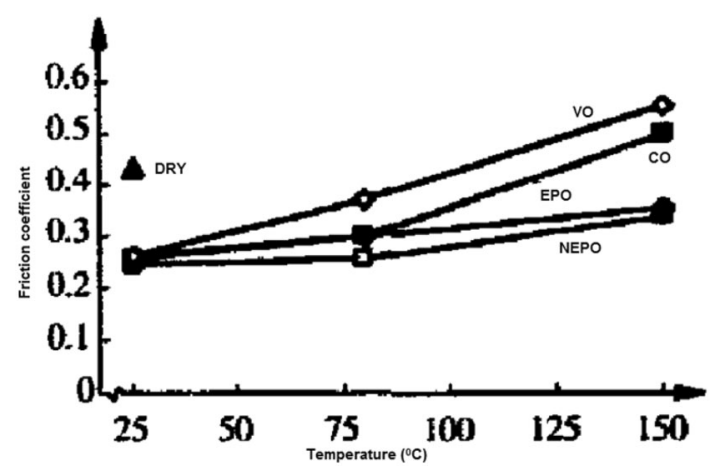

Figure 15. Evolution of friction coefficient vs temperature for DRY, CO, NEPO, EPO and VO during extrusion [73].

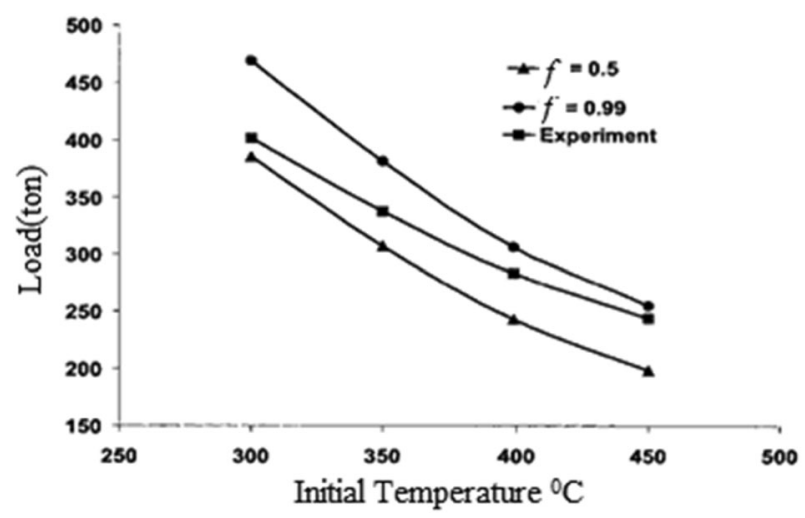

Figure 16. Predicted and experimental load variation with initial billet temperature for aluminium alloy 2024 [71].

Figure 16 shows that extrusion load increases with increase in frictional coefficient and decrease with increase in initial billet temperature [71].

$$
\mu=\frac{f \alpha}{\sqrt{3\left(1-f^{2} \alpha^{2}\right)}+\sqrt{3} \alpha^{\frac{n}{2}}} .
$$

Here $a=\frac{A_{\mathrm{a}}}{A_{\mathrm{i}}}$ where $A_{\mathrm{a}}$ is the actual contact area and $A_{\mathrm{i}}$ is the initial contact area.

In elastic friction, by Coulomb law

$$
\mu=\frac{F_{\mathrm{f}}}{F_{\mathrm{n}}}=\frac{\tau_{\mathrm{f}} A}{\sigma A}=\frac{\tau_{\mathrm{f}}}{\sigma} \Rightarrow \tau_{\mathrm{f}}=\mu \sigma .
$$

In plastic friction, by constant shear stress law

$$
\begin{gathered}
\tau_{f}=f \sigma=f_{\mathrm{s}} \frac{\sigma}{\sqrt{3}}=f_{\mathrm{s}} k_{\mathrm{s}}, \\
\Rightarrow f_{\mathrm{s}}=\frac{\tau_{\mathrm{f}}}{k_{\mathrm{s}}} .
\end{gathered}
$$

4.1f Temperature effect: Heat generations in micro-extrusion are less than the heat generated in conventional extrusion [76]. Gu and Davies [5] found that heat dissipation in UFGs increases with increase in extrusion speed as compared with CGs. Tensile strength in cold extrusion decreases with decreasing specimen size or increasing size

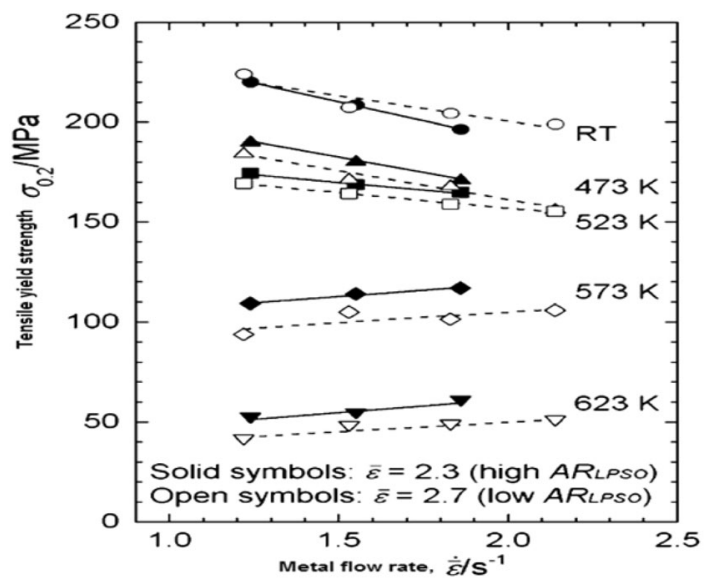

Figure 17. Average metal flow rate vs tensile yield strength at room and elevated temperature of extruded Mg97Zn1Y2 alloy [6]. 
(a)

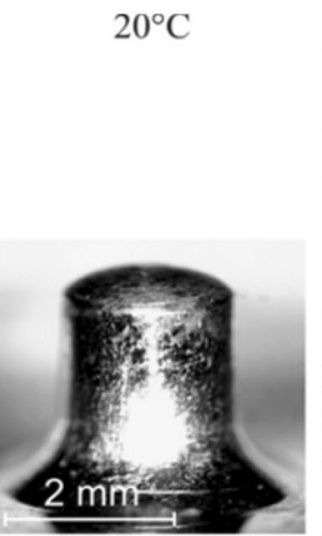

Aspect ratio 1.35

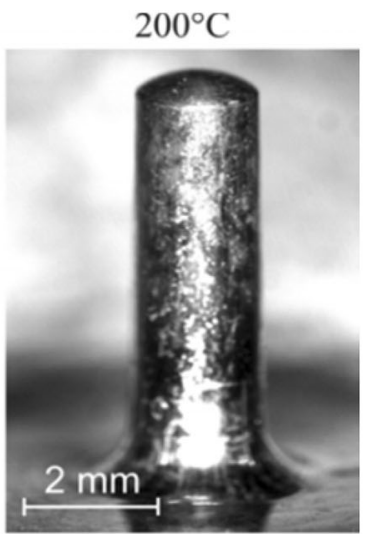

Aspect ratio 3.07 (b)

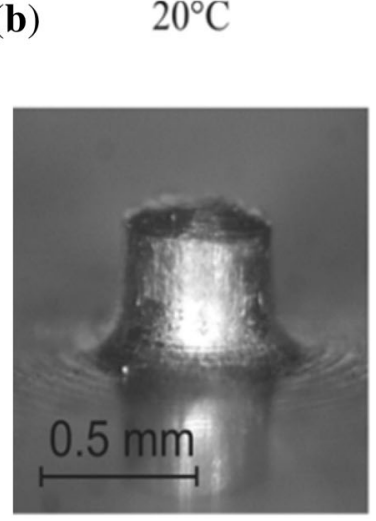

Aspect ratio 0.86

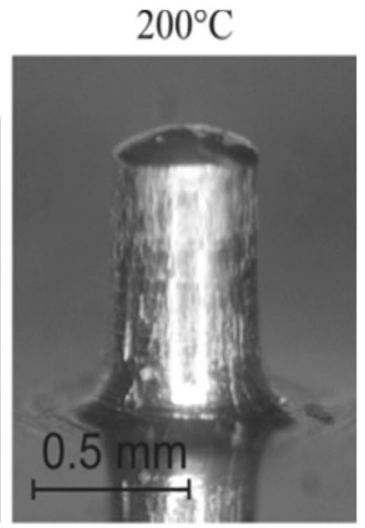

Aspect ratio 1.63

Figure 18. Effect of temperature on aspect ratio: (a) 2-mm pin diameter and (b) 0.5-mm pin diameter [22].

of a grain while in hot extrusion, tensile strength decreases with decreasing grain size [2]. Tensile strength at different $\mathrm{AR}_{\mathrm{LPSO}}$ (aspect ratio of long-period stacking order), equivalent strains, metal flow rates and temperature conditions during extrusion of $\mathrm{Mg} 97 \mathrm{Zn} 1 \mathrm{Y} 2$ alloy is given in figure 17 [6]. Hirano et al [6] observed that equivalent strain is higher for low $\mathrm{AR}_{\mathrm{LPSO}}$ (aspect ratio of long-period stacking order). They also found that tensile strength decreases with increase in temperature as well as $\mathrm{AR}_{\mathrm{LPSO}}$. An experimental work presented on copper shows that the aspect ratio of larger scale is much higher than that of micro-scale; also, aspect ratio increases with increase of working temperature keeping constant grain size without any lubrication as shown in figure 18 [22].

\subsection{Properties of extruded product through experimental and simulation}

This review paper already discussed about change in properties and microstructure such as tensile strength, hardness, ductility, \%age elongation, surface finish, grain size, dislocation density, etc. with change in affecting parameter (process, working condition, scale size, die, ultrasonic vibration, thickness, lubricant, temperature, etc.) for as-cast and UFG material. Following sections discuss observations on microstructure, extrusion load, surface roughness, flow behaviour, hardness, strength, fracture, texture, wear, etc. of micro-extruded product obtained from experimental and numerical modelling of cast and UFG material.

4.2a Microstructure: The microstructure in extruded pure copper is inhomogeneous for the CG and homogeneous for fine grains [67]. UFGs of $\mathrm{Al}$ alloy material show inhomogeneous flow with decreasing specimen size [77]. The inhomogeneous microstructure of as-cast grain distribution of Aluminium 6061 alloy is shown in figure 19a-c, where grains are elongated at the outer periphery (figure 19b) as compared with the central area, where punch load is acting, which does not allow the grain to elongate due to high frictional factors. In figure 19c, at reduced scale size, grain is elongated at the centre of punch as compared with an outer periphery due to the low frictional factor between punch and specimen at the centre. The investigation done on ECAP-based extruded pure copper material shows equi-
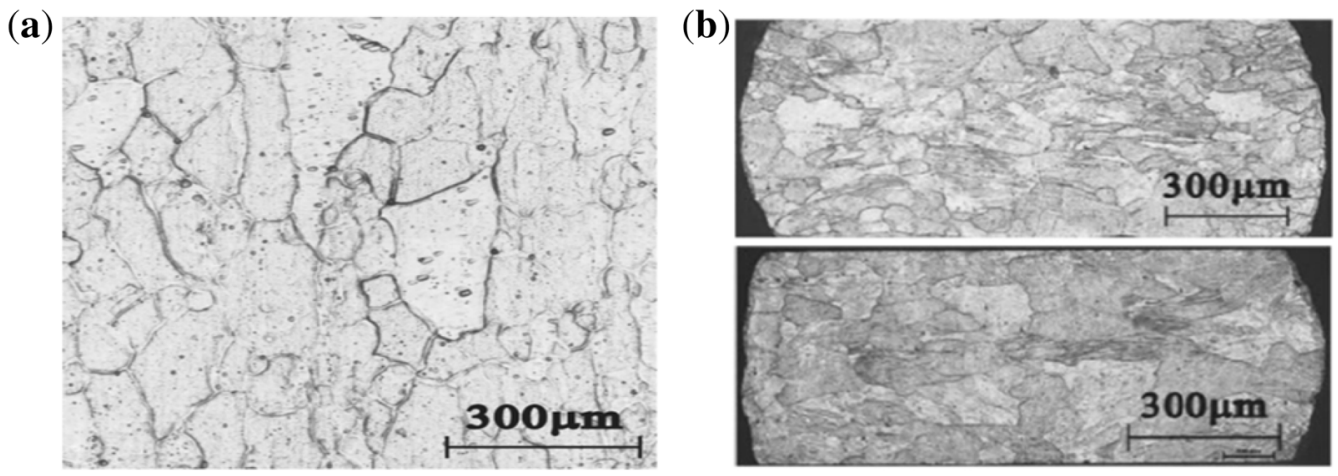

Figure 19. Microstructure of aluminium 6061 alloy: (a) initial microstructure and compressed sample with decreasing dimension, (b) $1 \times 1.5 \mathrm{~mm}^{2}$ and (c) $0.75 \times 1.125 \mathrm{~mm}^{2}$ [77]. 


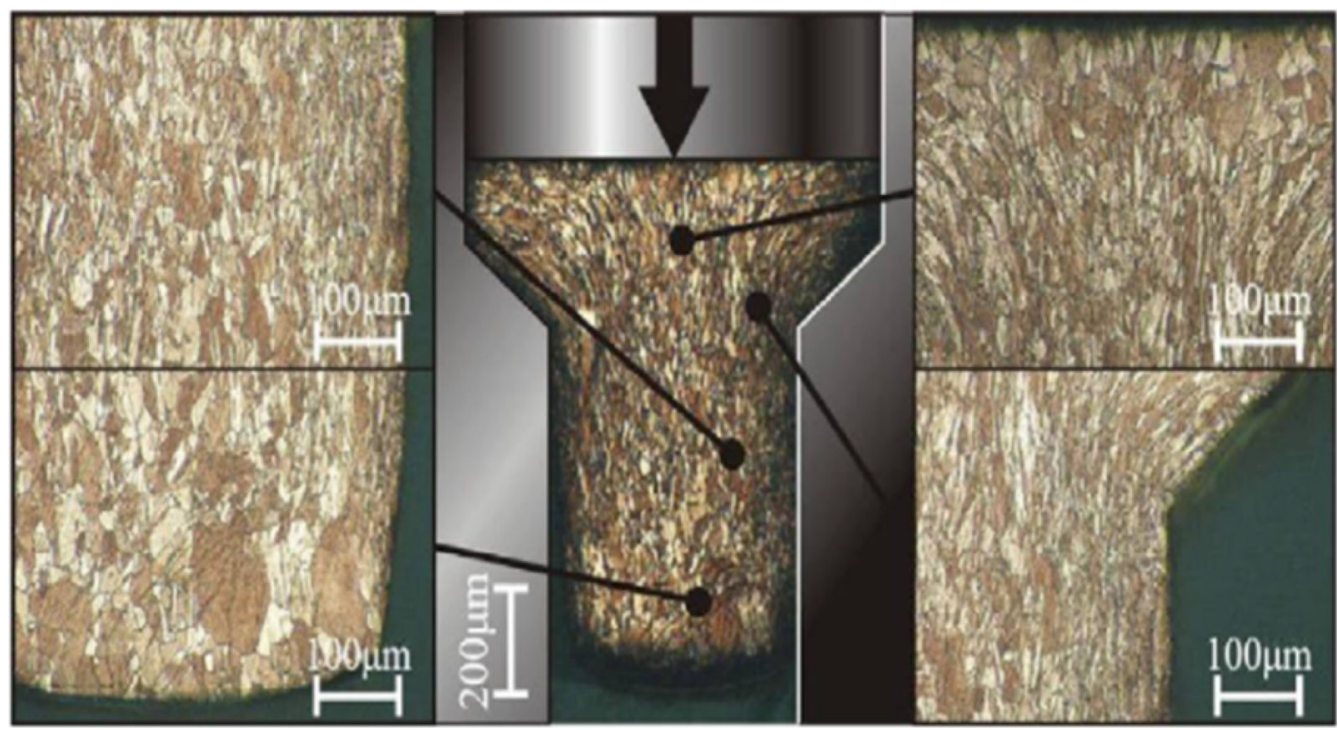

Figure 20. Microstructure of pure $\mathrm{Cu} 20-\mu \mathrm{m}$ grain [33].

axed structure (uniform grain size in all orientations) that appears after 8 passes [78]. Initial grain size of $23.9 \mu \mathrm{m}$ of AZ31 material during micro-gear formation through extrusion is refined to $4.1 \mu \mathrm{m}$ after 6 passes at $553 \mathrm{~K}$ [3]. Size of microstructure in the form of average grain diameter $\left(D_{\text {Avg }}\right)$ is determined using the longitudinal plane area $(S)$ and the number of grains $\left(N_{\mathrm{g}}\right)$ as given in Eq. (9) [74]. Researchers have used 20 and $150 \mu \mathrm{m}$ grain size of a copper specimen obtained through ECAP for further use during extrusion [67]. They observed that in case of fine grains $(20 \mu \mathrm{m})$, grain boundaries are not clear; this happened due to increase in material flow line with the decrease in grain size as shown in figure 20 .

$$
D_{\text {Avg }}=\frac{S}{N_{\mathrm{g}}} .
$$

Grain size observed through microstructure changes with numbers of passes and is limited up to a certain number of passes for a specified sample, working condition and die geometry. Hence, further study is needed to establish the condition in which homogeneous fine grains are possible.

4.2b Extrusion load: Ram force required during extrusion of CuZn30 alloy increases with decrease in grain size as observed from experimental and numerical results shown in figure 21 [4]. During extrusion of copper sample, ram force decreases with increasing grain size of sample; this is due to increasing frictional force between the billet and container wall [79]. Extrusion load required for UFG of $\mathrm{Al}$ prepared by ECAP process is more than that for the $\mathrm{CG}$ material as shown in figure 22 [11]. Extrusion load increases due to increase in numbers of grain during microextrusion of copper [67]. This happened due to increased friction with an increase in grain number. The harder the material, the higher the extrusion load [80]. In extrusion of C11000 alloy, loads increase with increasing height to diameter ratio [81]. In the extrusion of pure copper, punch load increases when backward and lateral flow of material is constrained, which increases the flow of inner material
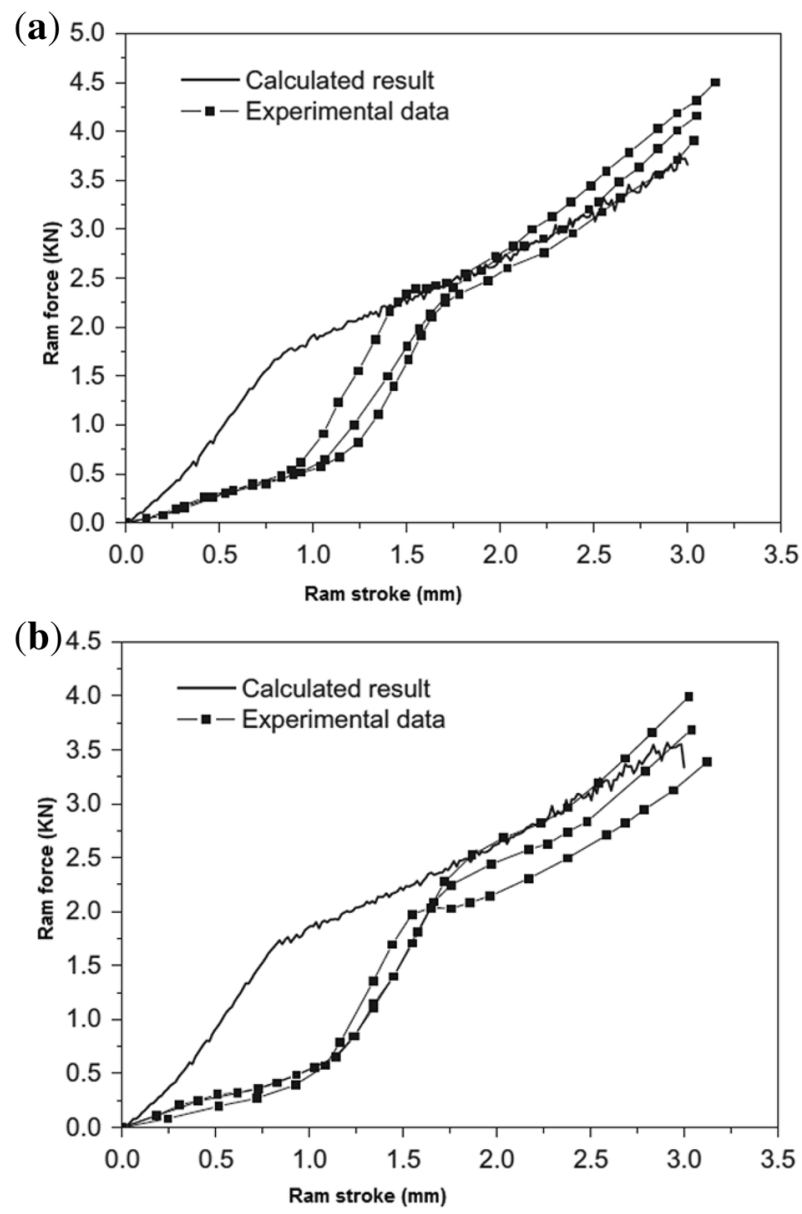

Figure 21. Load distribution per stroke with changing grain size: (a) $32 \mu \mathrm{m}$ and (b) $87 \mu \mathrm{m}$ [34]. 


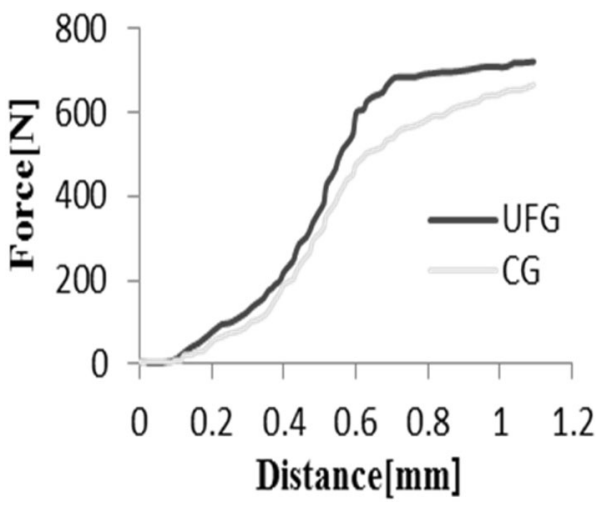

Figure 22. Force variation in CG and UFG aluminium [11].

faster than that of the outer material, resulting in longer extruded billet [82]. In a punching-blanking process for the formation of micro-pins of C11000, inhomogeneous mechanical property is observed in the dead zone of punchdie cavity entrance [83].

Result observed shows extrusion load increases continuously with decreasing grain size, increasing grain number, increasing friction coefficient during micro extrusion.

4.2c Flow stresses: Flow stress depends on number of outer surface grains and inner volume grains of the sample. SPD imposes very high strain in each pass, which minimizes the dislocation between grains and leads to increase in the numbers of grains [21]. Dislocation depends on inner volume grains rather than outer surface grains as observed through Eq. (10) [64, 84]. In case of decrease in specimen size at constant grain size, grains located inside the material are highly restricted compared with outer surface grains, resulting in increase in share of total grains $\left(N_{t}\right)$; hence flow stress reduces. With size miniaturization, share of surface grain $\left(N_{\mathrm{s}}\right)$ increases, which leads to lower resistance and less hardening against the deformation as compared with grains inside $\left(N_{\mathrm{i}}\right)$. Here, $\sigma_{\mathrm{s}}$ and $\sigma_{\mathrm{i}}$ are the flow stress of outer and inner surface grain, respectively:

$$
\sigma_{\mathrm{f}}=\frac{N_{\mathrm{s}} \sigma_{\mathrm{s}}+N_{\mathrm{i}} \sigma_{\mathrm{i}}}{N}
$$

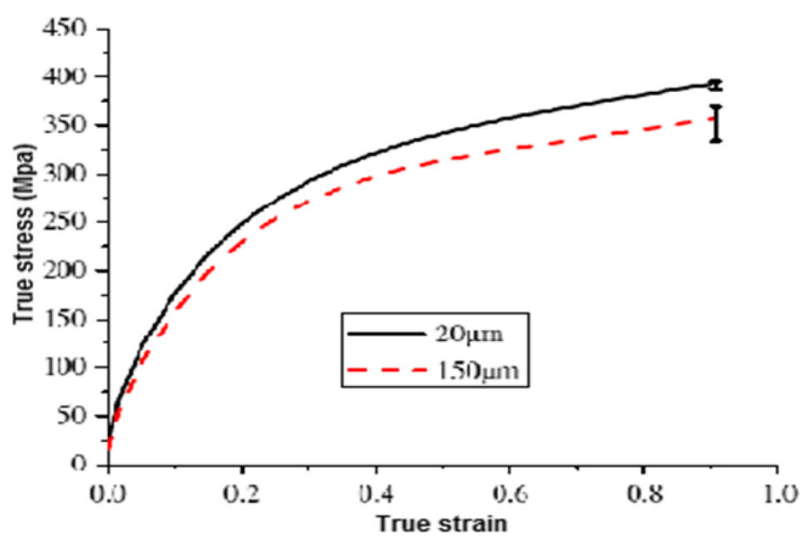

Figure 23. True stress-true strain curve for the flow [67].

$$
N_{t}=N_{s}+N_{i}
$$

Flow stress increases with reducing grain size or by an increasing number of grains over a constant surface area [7, 85]. Barbier et al [86] have used different flow stress models based on the grain size effect $(\alpha)$ and scale size effect $(\varphi)$ as given in Eqs. (11) and (12). Their observation shows that flow stress of material related to grain size effect is better than scale size effect, where $\sigma_{\mathrm{i}}$ is the initial yield stress and $p$ is the strain hardening component. Flow stress that is related to surface grain depends on the cross-sectional length $\left(w_{\mathrm{o}}\right)$, cross-sectional width $\left(t_{\mathrm{o}}\right)$ and average grain size $(L)$ as shown in Eq. (11). Similarly, scale size effect of Eq. (12) is related to ratio of initial height $\left(H_{\mathrm{o}}\right)$ to grain size. Barbier et al [86] also observed in their model that flow stress increases with increasing ratio of initial height to average grain size, which is valid for micro-extrusion [87]. High friction and low temperature at the contact surface of the tool-workpiece interface is also a reason for inhomogeneous flow with higher flow stress as observed in extrusion of pure copper [82]. In extrusion, surface grain after shearing increases the hardness of material, resulting in increase of flow stress [79]. Chan et al [67] observe that flow stress in micro-extrusion of pure copper is higher for UFG material as compared with CG material as shown in figure 23.

$$
\begin{gathered}
\sigma_{\mathrm{f}}=\sigma_{\mathrm{i}}+274 \alpha^{-0.24}\left[1-\exp \left(-1.5 \alpha^{0.14} \varepsilon^{-p}\right)\right] \\
\sigma_{\mathrm{f}}=\sigma_{\mathrm{i}}+173 \varphi^{-0.23}\left[1-\exp \left(-2.01 \varphi^{0.13} \varepsilon^{-p}\right)\right] \\
\alpha=1-\frac{\left(\mathrm{w}_{\mathrm{o}}-2 L\right)\left(t_{\mathrm{o}}-2 L\right)}{w_{\mathrm{o}} t_{\mathrm{o}}} \text { and } \varphi=\frac{H_{\mathrm{o}}}{L} .
\end{gathered}
$$

They found that high friction and lower material temperature or work hardening can increases the flow stress, where the flow stress of UFG material is higher than that of the CG material.

4.2d Surface roughness: Surface roughness depends on grain size and their height, which changes the frictional coefficient. In a deep drawing, large size grains show uneven deformation with poor surface finish [88]. Increasing grain size increases the asperity (roughness), resulting in increase of efficiency of lubrication and hence interfacial friction force decreases during compression of copper [89]. According to Bai and Yang [90], initial surface roughness of $97 \mathrm{~nm}$ decreased to $50 \mathrm{~nm}$ with decreasing frequency of vibration during forging of phosphor bronze C5191. Cups of 1 and $2 \mathrm{~mm}$ extruded at different roughnesses of the die during double cup extrusion of CuZn15 material are shown in figure 24 [10]. They observed that frictional coefficient increases with fine surface die as compared with rough surface die in a micro-extrusion (1 $\mathrm{mm}$ ), which is not valid in meso-scale.

4.2e Flow behaviour of sample: Flow behaviour of extruded sample changes with changing grain size and sample dimension. Curvature of extruded pin taken from $\mathrm{CG}$ material is more than that of UFG material as shown in 

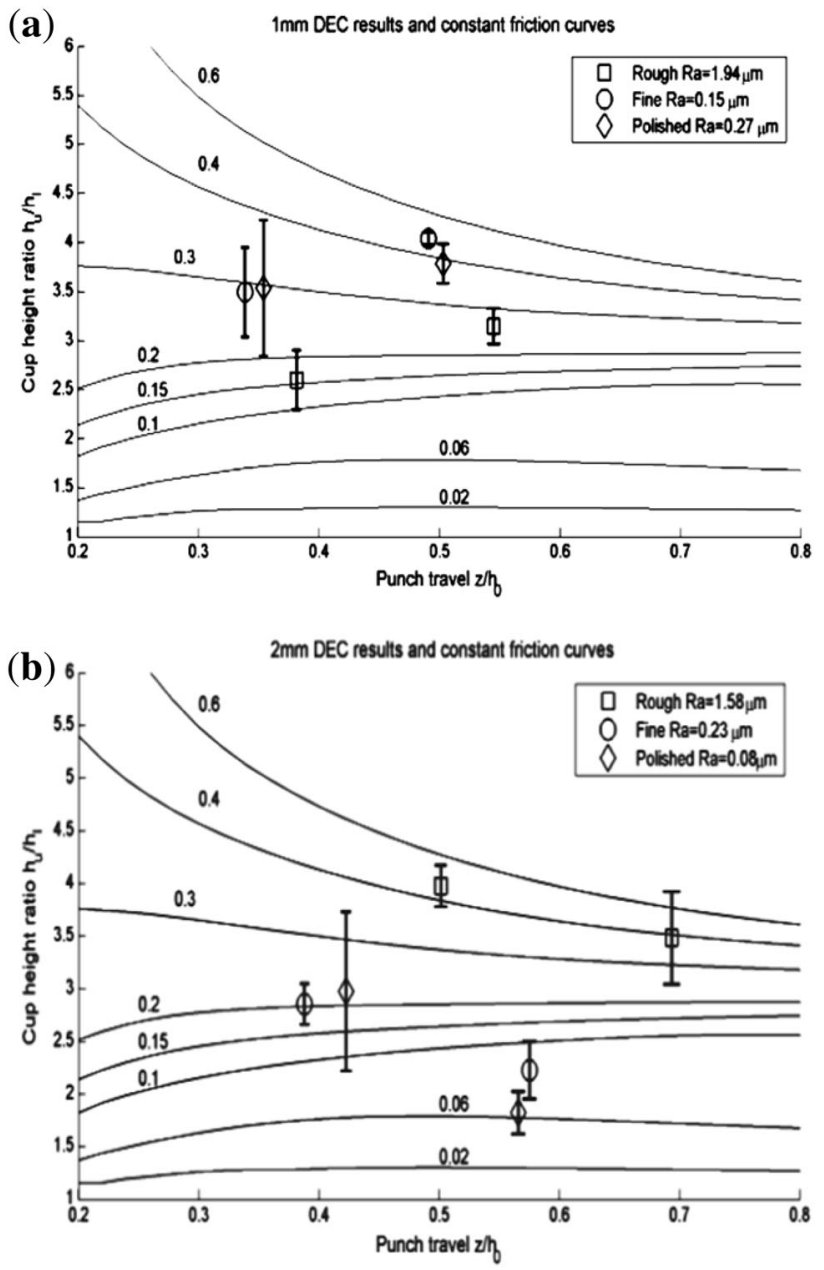

Figure 24. Effect of roughness in double cup extrusions: (a) 1 $\mathrm{mm}$ and (b) $2 \mathrm{~mm} \mathrm{[10].}$

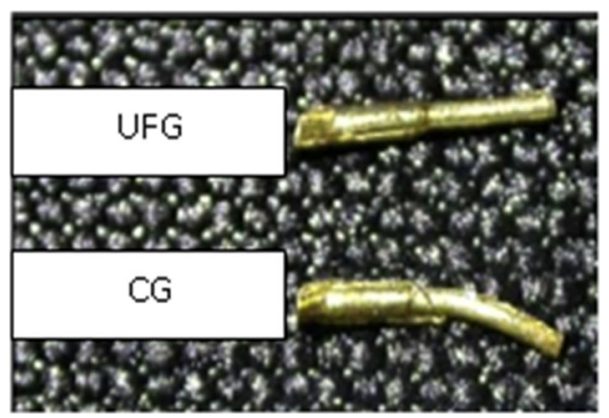

Figure 25. Flow pattern of CG and UFG sample [8].

figure 25 [8, 91]. Curvature depends upon the size of grains as well as the grains degrees of freedom (DOF). The large number of grains in UFG material restricts the DOF of other grains. Hence the flow of UFG has a small curvature as compared with $\mathrm{CG}$. Chan and $\mathrm{Fu}$ [79] conducted extrusion of pure copper and observed that inner material flow is higher in UFG as compared with CG material, resulting in increase of extruded length. Similarly, they
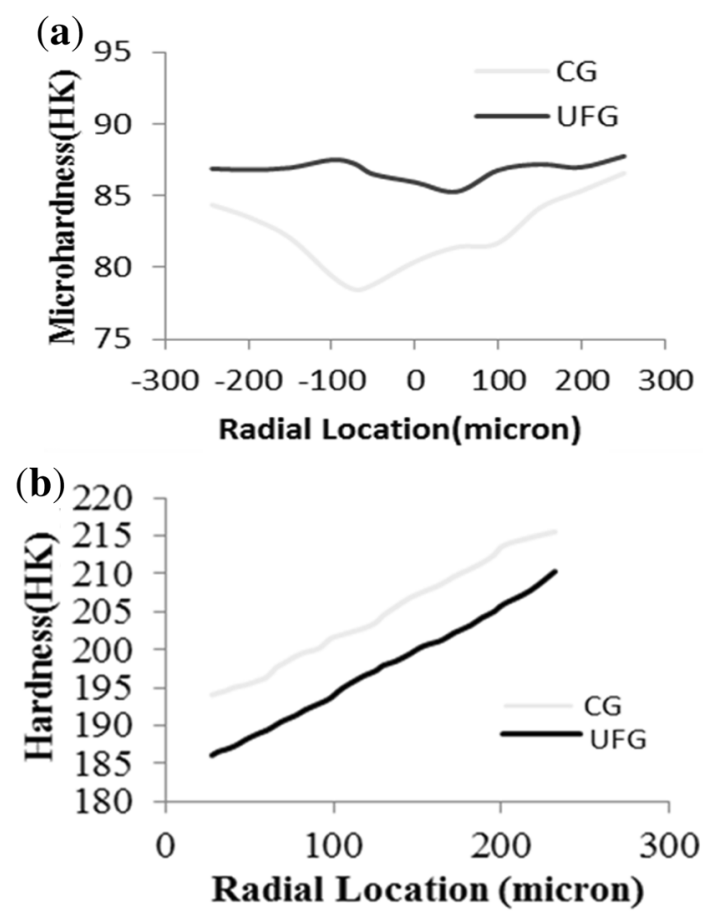

Figure 26. Micro-hardness of CG and UFG material (a) before and (b) after extrusion [8].

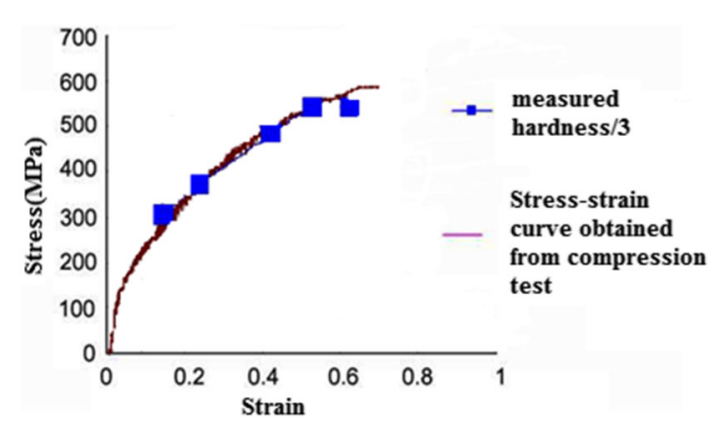

Figure 27. Comparison of flow stress and hardness in down scale for constant grain size [60].

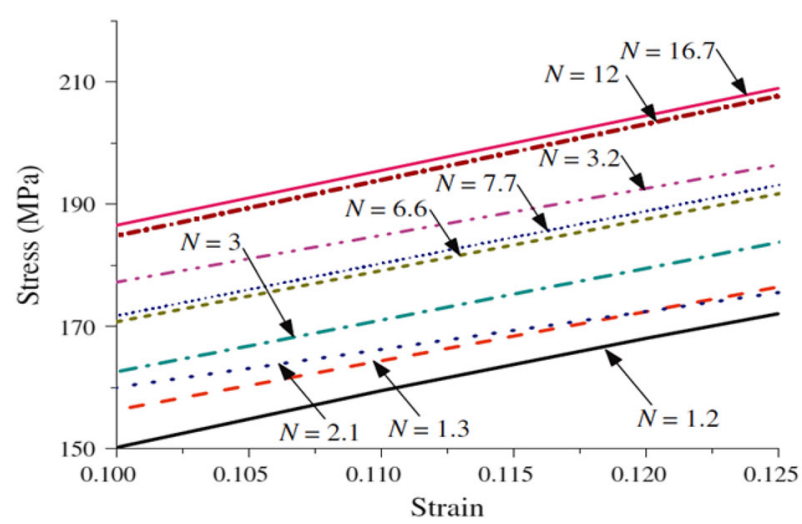

Figure 28. Stress-strain curve (for $N>1$ ) [84]. 

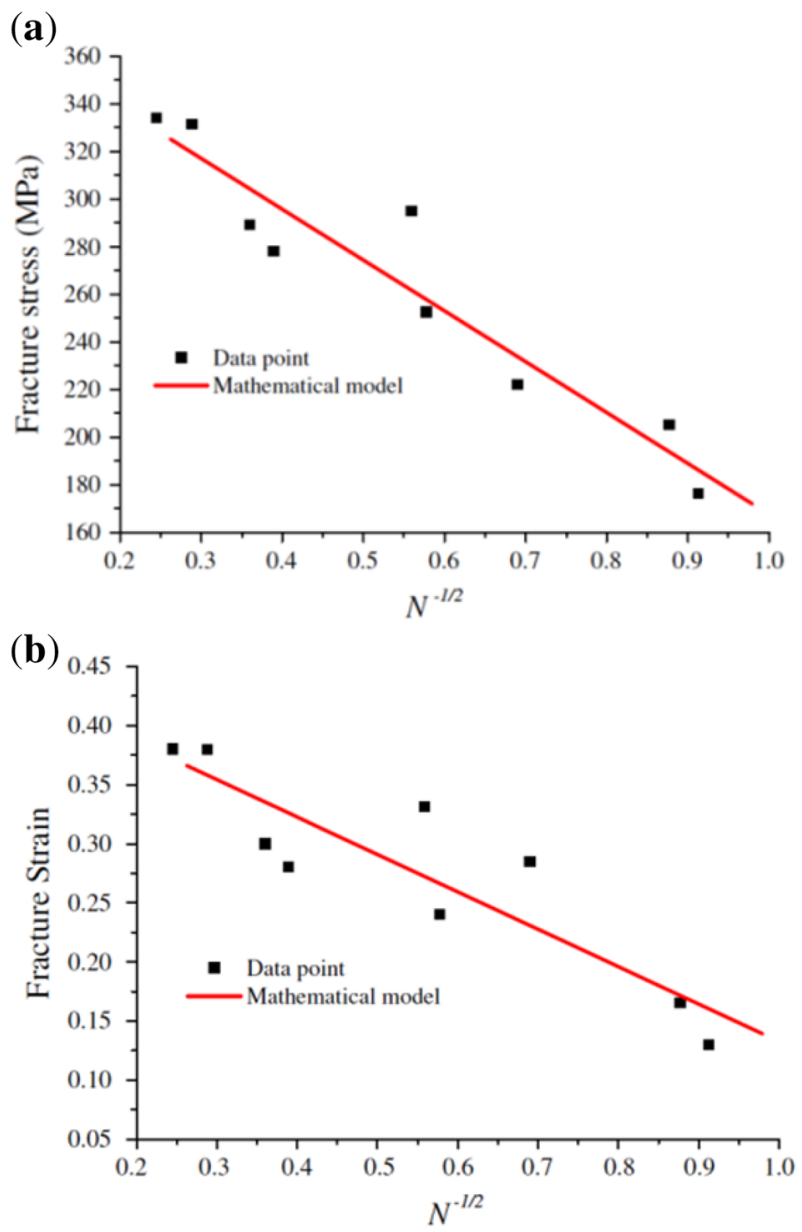

Figure 29. Relation between fracture stress or strain and $N^{-1 / 2}$ [84].

observed that lateral flow is higher in CG as compared with UFG material. Flow of material in backward extrusion is more than in forward extrusion [92] for UFG material. 4.2f Hardness: Micro-hardness of CuZn30 UFG material before extrusion is more than that of CG material, but it is altered after micro-extrusion for a given specimen size as shown in figure 26a and b [8]. According to Bai and Yang [90], hardness of phosphor bronze C5191 increases from 1.5 to $3 \mathrm{GPa}$ with decrease in frequency of vibration during forging. They observed that hardness increases up to 20 vibration cycles and remain constant thereafter. Flow stress of $\mathrm{Cu}-\mathrm{Zn}$ alloy material with increasing hardness $(H)$ using Eq. (13) is shown in figure 27 [60]. Dislocation depends on inner volume grain rather than outer surface grain and flow stress is proportional to hardness of material; hence, central region of extruded sample is harder than surface region [93].

$$
\sigma_{\mathrm{f}}=\frac{H}{3}
$$

4.2g Yield strength, tensile strength and ultimate strength: Chen and Tsai [60] and Fu and Chan [84] determined that strength of the material depends on $T / D$ ( $T=$ thickness of grain, $D=$ average grain diameter) ratio denoted as $N$. They observed that yield strength decreases with decreasing $N$ as shown in figure 28 and subsequently increases with decrease of $N$ below 1. Yield strength and tensile strength of 2-mm billet at high strain rate $(0.01)$ and at high temperature $(520 \mathrm{~K})$ decrease with decreasing grain size [2].

4.2h Fracture: Fracture is failure of material when the continuous applied load reaches fracture stress. Failures happen due to slip and crack or dislocation of grains [94]. Fracture stresses $\left(\sigma_{\mathrm{c}}\right)$ and fracture strain $\left(\varepsilon_{\mathrm{c}}\right)$ are inversely proportional to the square root of $N$, i.e., $T / D$ ratio ( $T=$ thickness of grain, $D$ $=$ average grain diameter) as given in Eqs. (14) and (15) and shown in figure 29a and b [84], where h, k, i, 1 are used for quantitative study of fracture stress-strain magnitude for different materials and change in fracture stress-strain with corresponding $N$. Fu and Chan [84] observed that $\sigma_{\mathrm{c}}$ and $\varepsilon_{\mathrm{c}}$ of pure copper linearly decrease with decrease in grain diameter.

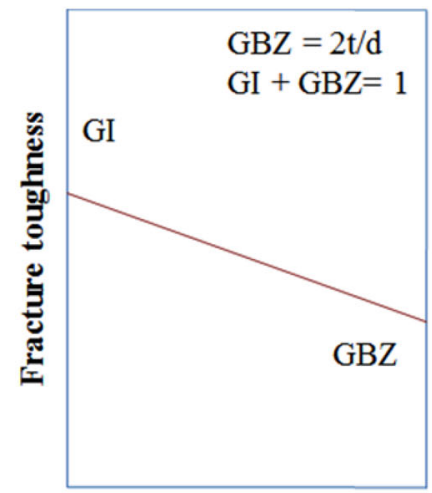

GBZ

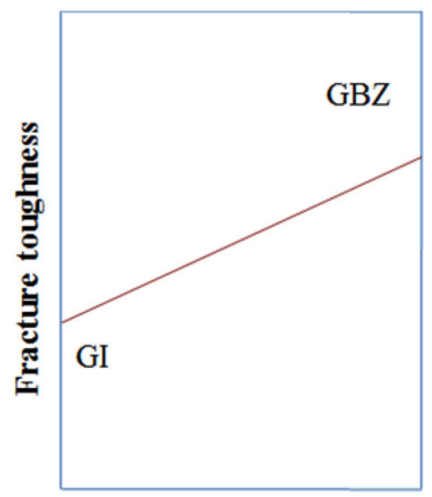

GBZ

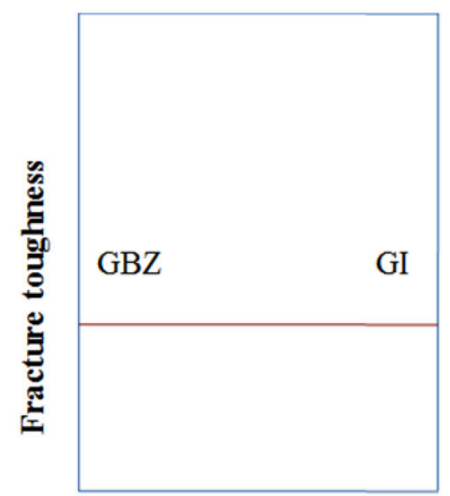

GBZ

Negative slop

Positive slop

Zero slop

Figure 30. Slope for fracture toughness [94]. 
Either decreasing specimen size or increasing grain size results in decrease of fracture toughness [95]. According to Rosochowska et al [92], formation of micro-pin of $0.15-\mathrm{mm}$ diameter using A1070 UFG alloy led to shear localization and fracture. Fracture stress in material increases with a positive slope (grain boundary zone $>$ grain interior) and decreases with negative slope (grain boundary zone $<$ grain interior) while fracture toughness in zero slope condition is independent of grain boundary as shown in figure 30 [94]. They present a fracture toughness $\left(f_{\mathrm{t}}\right)$ model for polycrystalline material as given in Eq. (16), where $f_{\mathrm{t}}^{\mathrm{GBZ}}, f_{\mathrm{t}}^{\mathrm{ig}}$ are the fracture toughness of grain boundary zone and grain interior, respectively, while $v_{\mathrm{GBZ}}, v_{\mathrm{GI}}$ are the volume fractions of grain boundary zone and grain interior. Observation shows that grain size dependence of yield strength is in contrast with the Hall-Pitch relation and hence yield strength also decreases with lowering grain size. Reducing the scale size from macro to micro, chance of growth and collision of micro-voids during plastic deformation are enhanced, which is the reason for fracture of material [79].

$$
\begin{gathered}
\sigma_{\mathrm{c}}=h+i N^{\frac{-1}{2}}, \\
\varepsilon_{\mathrm{c}}=\mathrm{k}+1 \mathrm{~N}^{-1 / 2}, \\
f_{\mathrm{t}}=f_{\mathrm{t}}^{\mathrm{GBZ}} v_{\mathrm{GBZ}}+f_{\mathrm{t}}^{\mathrm{GI}} v_{\mathrm{GI}},
\end{gathered}
$$

where $v_{\mathrm{GBZ}}=\frac{2 t}{d}$ and $v_{\mathrm{GI}}=1-\frac{2 t}{d}$.

4.2i Texture: Textures are complex visual patterns characterized by brightness, colour, slope, size, etc. [96]. Such visual pattern properties are inferred to provide information about lightness, uniformity, density, roughness, regularity, linearity, frequency, phase, directionality, coarseness, randomness, fineness, smoothness, granulation, etc. of the texture as a whole [97]. In isotropic materials, grain distribution is uniform, but due to decrease in specimen size, this uniformity changes [84]. The texture images of extruded product before and after the micro-extrusion of $\mathrm{CG}$ and fine grain material are shown in figure 31a and b [8]. They observed from pole image that extruded sample has symmetry texture and un-extruded sample has non-symmetry texture, resulting in weak texture property as compared with the extruded sample. Despite similar looking symmetricity of CG and UFG material for extruded sample, the texture of UFG is better as compared with CG. Highstrength product manufactured by ECAP processes restores previous texture after extrusion [3].

$4.2 \mathrm{j}$ Wear: Wear resistance of ultrafine material increases due to the increase in number of surface grains, hardness or strength of materials [98]. The wear resistance property of as-cast 6061 Al material is improved after extrusion processes [99]. According to Soltani et al [100] wear resistance is improved in hot extrusion. Wear of SPD process material is not uniform for all materials, but increases with grain refinement. (a)

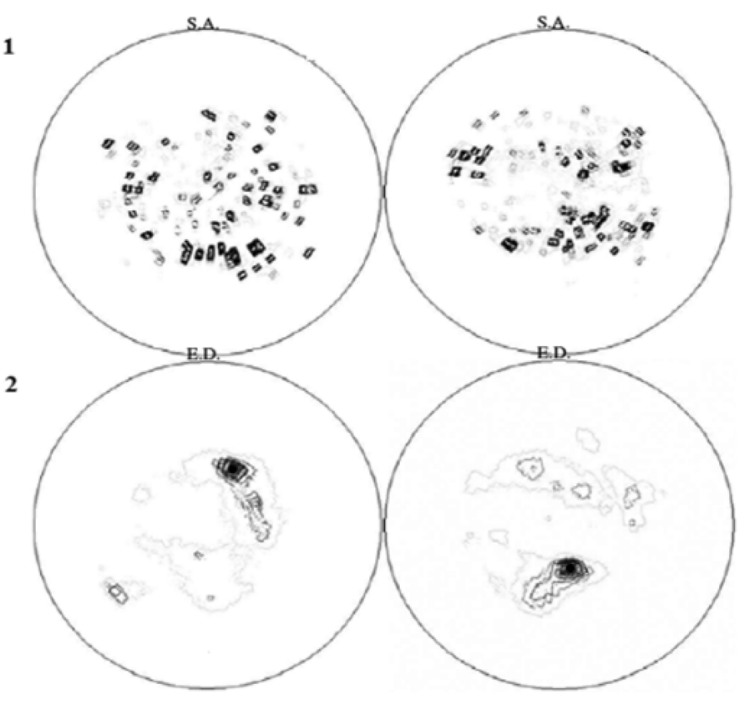

(b)

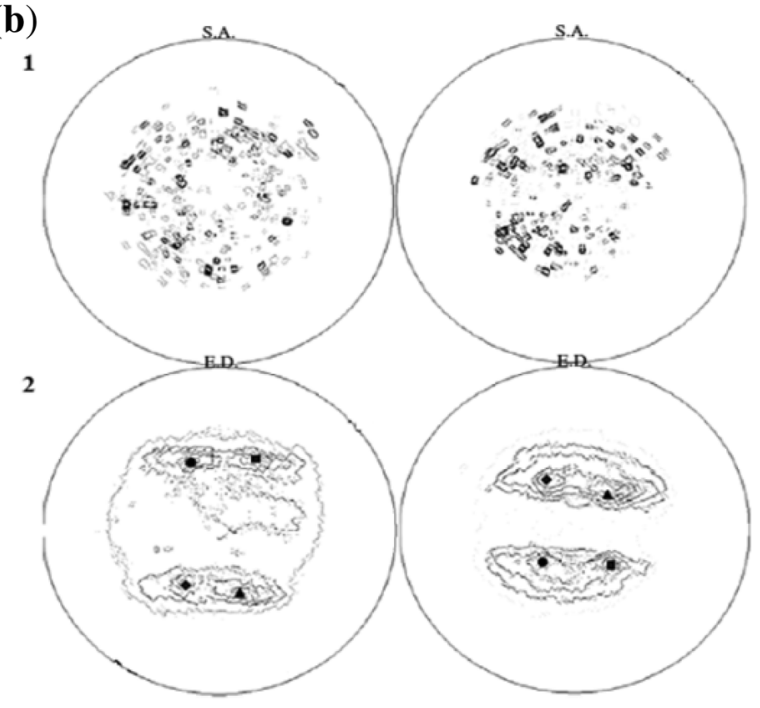

Figure 31. Texture of (a) coarse grain: (1) un-extruded and (2) extruded and (b) fine grained: (1) un-extruded and (2) extruded [99].

\section{Conclusions}

From the above literature review, following conclusions have been derived.

\subsection{As-cast and UFG material}

Grain distribution in as-cast material is non-homogeneous and varies from sub-mm to sub- $\mu \mathrm{m}$ range. Grain growth is restricted by adding high-strength alloying element during casting. Hardness of as-cast material increases with fast cooling rate. Strength and toughness of as-cast material increase with low pouring speed whereas defect-free microstructures are achieved at low pouring temperature. Low pressure die casting is superior to sand casting, gravity 
die casting and high-pressure die casting in terms of improved mechanical properties of cast material. UFGs achieved through SPD have higher strength to weight ratio. Lower angle grain boundary produces finer grains and size of grain increases with increasing mis-orientation angle. Higher frictional lubricant decreases the material porosity, resulting in increase of ductility and toughness.

\subsection{Micro-extrusion}

The parameters that affect the properties and microstructure of samples used in micro-extrusion are die geometry, die strength, specimen selection (such as UFG or as-cast material), frictional condition, temperature condition, extrusion load, vibration frequency, etc. The failure rate of cold extrusion die is higher as compared with hot extrusion die. Deformation load and hardness required to deform the billet increase with increasing die entry angle. Deformation of CG shows inhomogeneous microstructure with poor surface finish. SPD minimizes dislocation between grains, due to which number of grains increases. Dislocation depends on inner volume grains rather than outer surface grains and hence UFG material requires higher ram force than that for CG material. Curvature of pin taken from CG material is larger than that for UFG material. Micro-hardness of UFG material before extrusion is more than that for CG material, which is altered in micro-extrusion. UFG material shows inhomogeneous flow with decreasing specimen size and friction factor increases with decreasing scale ratio. Aspect ratio of specimen gives higher equivalent strain at low $\mathrm{AR}_{\mathrm{LPSO}}$, which decreases with increasing working temperature for constant grain size. Decrease in specimen thickness leads to fracture strain. Heat releasing capacity of UFG material increases with increasing extrusion speed. For a high-strength product manufactured by ECAP processes, its previous texture is restored after extrusion. Textures of UFG material are better than those of CG material. Wear property of UFG material increases with increase in number of surface grains, hardness or strength of material. Decreasing frequency of vibration increases hardness of material. Better surface finish at low load is achieved by the use of ultrasonic vibration during extrusion.

\section{References}

[1] Okazaki Y, Mishima N and Ashida K 2002 Microfactory and micro machine tool. In: Proceedings of the KoreaJapan conference on positioning technology, Daejeon, Korea

[2] Saotome Y and Inoue A 1994 Superplastic micro-forming of microstructure. In: Proceedings of the IEEE workshop on micro-electro-mechanical systems, MEMS'94, pp. 343-348
[3] Kim W J and Sa Y K 2006 Micro-extrusion of ECAP processed magnesium alloy for production of high strength magnesium micro-gears. Scr. Mater. 54: 1391-1395

[4] Liu J G, Fu M W and Chan W L 2012 A constitutive model for modeling of the deformation behavior in micro-forming with a consideration of grain boundary strengthening. Comput. Mater. Sci. 55: 85-94

[5] Gu C F and Davies C H J 2010 Thermal stability of ultrafine-grained copper during high speed micro-extrusion. Mater. Sci. Eng. 527(7-8): 1791-1799

[6] Hirano M, Yamasaki M, Hagihara K, Higashidam K and Kawamura K 2010 Effect of extrusion parameters on mechanical properties of Mg97Zn1Y2 alloys at room and elevated temperatures. Mater. Trans. 51(9): 1640-1647

[7] Cao J, Krishnan N, Wang Z, Lu H, Liu W K and Swanson A 2004 Micro-forming: experimental investigation of the extrusion process for micropins and its numerical simulation using RKEM. J. Manuf. Sci. Eng. 126(4): 642-652

[8] Parasız S A, Kinsey B L, Mahayatsanunb N and Caob J 2011 Effect of specimen size and grain size on deformation in microextrusion. J. Manuf. Process. 13: 153-159

[9] Engel U 2006 Tribology in micro-forming. Wear 260: 265-273

[10] Eriksen R S, Weidel S and Hansen H N 2010 Tribological influence of tool surface roughness within micro-forming. Int. J. Mater. Form. 3(1): 419-422

[11] Rosochowski A, Presz W, Olejnik L and Richert M 2007 Micro-extrusion of ultra-fine grained aluminium. Int. J. Adv. Manuf. Technol. 33: 137-146

[12] Bunget C and Ngaile G 2011 Influence of ultrasonic vibration on micro-extrusion. Ultrasonics 51: 606-616

[13] Toth L S, Lapovok R, Molotnikov A, Gu C, Fundenberger J J and Davies C H J 2010 Texture evolution during microdrawing of ultrafine grained copper. Mater. Sci. Eng. A 527(18-19): 4633-4640

[14] Cho H, Hwang D Y, Lee B S and Jo H H 2007 Fabrication of micro condenser tube through direct extrusion. J. Mater. Process. Technol. 187-188: 645-648

[15] Qin Y 2010 Micromanufacturing engineering and technology, William Andrew (ed). Oxford: Elsevier Science, pp. 1-23

[16] Alting L, Kimura F, Hansen H N and Bissacco G 2003 Micro-engineering. CIRP Ann. Manuf. Technol. 52(2): 635-657

[17] Masuzawa T 2000 State of the art of micromachining. CIRP Ann. Manuf. Technol. 49(2): 473-488

[18] Geiger M, Kleiner M, Tiesler N and Engle U 2001 Microforming. Ann. CRIP 50(2): 445-462

[19] Geiger M, Messner A and Engel U 1997 Production of microparts-size effect in bulk metal forming, similarity theory. Prod. Eng. 4: 55-58

[20] Valiev R Z, Korznikov A V and Mulyukov R R 1993 Structure and properties of ultrafine-grained materials produced by severe plastic deformation. Mater. Sci. Eng. A 168: $141-148$

[21] Segal V M 1995 Materials processing by simple shear. Mater. Sci. Eng. A 197: 157-164

[22] Eichenhüller B, Engel U and GeißdörferS S 2008 Process parameter interaction in micro-forming. Int. J. Mater. Form. 1: 451-454 
[23] Taylor P R 1983 An illustrated history of lost wax casting. In: Proceedings of the 17th annual BICTA conference, Washington, DC

[24] Flemings M C 1974 Solidification processing. Metall. Trans. 5(10): 2121-2134

[25] DeGarmo E P, Black J T, Kohser R A and Klamecki B E 2003 Solutions manual to accompany. Materials and processes in manufacturing. Ninth Edition, John Wiley and Sons, pp 1-355

[26] Armstrong R, Codd I, Douthwaite R M and Petch N J 1962 Plastic deformation of polycrystalline aggregate. Philos. Mag. 7(73): 45-58

[27] Matisková D, Gašpar Š and Mura L 2013 Thermal factors of die casting and their impact on the service life of moulds and the quality of castings. Acta Polytechn. Hung. 10(3): $65-78$

[28] Wang Y C, Li D Y, Peng Y H and Zeng X Q 2007 Numerical simulation of low pressure die casting of magnesium wheel. Int. J. Adv. Manuf. Technol. 32: 257-264

[29] Ahmad R, Talib N A and Asmael M B A 2013 Effect of pouring temperature on microstructure properties of $\mathrm{Al}-\mathrm{Si}$ LM6 alloy sand casting. Appl. Mech. Mater. 315: 856-860

[30] Batyshev K A 2012 Casting of aluminum alloys with pressure crystallization part 2. Met. Sci. Heat Treat. 54: 1-2

[31] Yue T M and Chadwick G A 1996 Casting of aluminum alloys with pressure crystallization part 2. Met. Sci. Heat Treat. 58: 302-307

[32] Hajjaria E and Divandari M 2008 An investigation on the microstructure and tensile properties of direct squeeze cast and gravity die cast 2024 wrought $\mathrm{Al}$ alloy. Mater. Des. 29: 1685-1689

[33] Obiekea K, Aku S Y and Yawas D 2012 Influence of pressure on the mechanical properties and grain refinement of die cast aluminum A1350 alloy. Adv. Appl. Sci. Res. 3(6): 3663-3673

[34] Bonollo F, Urban J, Bonatto B and Botter M 2005 Gravity and low pressure die casting of aluminium alloys: a technical and economical benchmark. La Metall. Ital. (6): 23-32

[35] Fu P, Luo A A, Jiang H, Peng L, Yu Y, Zhai C and Sachdev A K 2008 Low-pressure die casting of magnesium alloy AM50: response to process parameters. J. Mater. Process. Technol. 205: 224-234

[36] Gertsman V Y, Li J, Xu S, Thomson J P and Sahoo M 2005 Microstructure and second-phase particles in low- and highpressure die-cast magnesium alloy AM50. Metall. Mater. Trans. A 36(8): 1989-1997

[37] Easton M and John St D 1999 Grain refinement of aluminium alloys: part I. The nucleant and solute paradigmsa review of the literature. Metall. Mater. Trans. A 30: $1613-1623$

[38] Chandrashekar T, Muralidhara M K, Kashyap K T and Rao P R 2009 Effect of growth restricting factor on grain refinement of aluminum alloys. Int. J. Adv. Manuf. Technol. 40: 234-241

[39] Jaradeh M and Carlberg T 2005 Effect of titanium additions on the microstructure of DC-cast aluminium alloys. Mater. Sci. Eng. A 413-414: 277-282

[40] Shouxun J, Douglas W, Yun W, Mark W and Zhongyun F 2013 Effect of Ti addition on mechanical properties of high pressure die cast Al-Mg-Si alloys. Mater. Sci. Forum 765: 23-27

[41] Emamy M, Emami A R, Khorshidi R and Ghorbani M R 2013 The effect of Fe-rich intermetallics on the microstructure, hardness and tensile properties of $\mathrm{Al}-$ Mg2Si die-cast composite. Mater. Des. 46: 881-888

[42] Huang J Y, Zhu Y T, Jiang H and Lowe T C 2001 Microstructures and dislocation configurations in nanostructured $\mathrm{Cu}$ processed by repetitive corrugation and straightening. Acta Mater. 49(9): 1497-1505

[43] Saito Y, Utsunomiya H and Suzuki H 1999 Proposal of novel continuous high straining process-development of conshearing process. In: Proc. of 6th ICTP, Advanced Technology of Plasticity, Nuremberg, Germany, edited by M. Geiger, pp. 2459-2464

[44] Harai Y, Ito Y and Horita Z 2008 High-pressure torsion using ring specimens. Scr. Mater. 58(6): 469-472

[45] Korbel A and Richert M 1985 Formation of shear bands during cyclic deformation of aluminium. Acta Metall. 33(11): 1971-1978

[46] Nakamura K, Neishi K, Kaneko K, Nakagaki M and Horita Z 2004 Development of severe torsion straining process for rapid continuous grain refinement. Mater. Trans. 45(12): 3338-3342

[47] Shin D H, Park J J, Kim Y S and Park K T 2002 Constrained groove pressing and its application to grain refinement of aluminium. Mater. Sci. Eng. A 328: 98-103

[48] Ghosh A K and Huang W 1999 Severe deformation based process for grain subdivision and resulting microstructures in investigations and applications of severe plastic deformation. In: Lowe T C and Valiev R Z (Eds.) Proceedings of the NATO advanced research workshop, Moscow. Dordrecht: Kluwer Academic Publishers, pp. 29-36

[49] Segal V M 1977 The method of material preparation for subsequent working. USSR Patent 575892

[50] Furukawa M, Iwahashi Y, Horita Z, Nemoto M and Langdon T G 1998 The shearing characteristics associated with equal-channel angular pressing. Mater. Sci. Eng. 257: 328-332

[51] Lugo N, Llorca N, Sunol J J and Cabrera J M 2010 Thermal stability of ultrafine grains size of pure copper obtained by equal-channel angular pressing. J. Mater. Sci. 45: 2264-2273

[52] Beyerlein I J, Field R D, Hartwig K T and Necker C T 2008 Texture development in two-pass ECAE-processed beryllium. J. Mater. Sci. 43: 7465-7473

[53] Furukawa M, Horita Z, Nemoto M and Langdon TG 2000 Achieving superplasticity at high strain rates using equal channel angular pressing. Mater. Sci. Technol. 16(11-12): 1330-1333

[54] Molnar P, Jager A and Lejcek P 2012 The role of low-angle grain boundaries in multi-temperature equal channel angular pressing of $\mathrm{Mg}-3 \mathrm{Al}-1 \mathrm{Zn}$ alloy. J. Mater. Sci. 47: 3265-3271

[55] Chen Y C, Huang Y Y, Chang C P and Kao P W 2003 The effect of extrusion temperature on the development of deformation microstructures in 5052 aluminium alloy processed by equal channel angular extrusion. Acta Mater. 51: 2005-2015 
[56] Shokuhfar A and Nejadseyfi O 2014 The influence of friction on the processing of ultrafine-grained/nanostructured materials. Mater. Eng. Perform. 23(3): 1038-1048

[57] McKenzie P W J and Lapovok R 2010 ECAP with back pressure for optimum strength and ductility in aluminium alloy 6016. Part 2: mechanical properties and texture. Acta Mater. 58(9): 3212-3222

[58] Xu C and Langdon T G 2007 The development of hardness homogeneity in aluminium and an aluminum alloy processed by ECAP. J. Mater. Sci. 42: 1542-1550

[59] Bauser M, Sauer G and Siegert K 2006 Extrusion, 2nd edition. Geauga County, OH: ASM International. ISBN-10: 0-87170-873-X

[60] Chen F K and Tsai J W 2006 A study of size effect in micro-forming with micro-hardness tests. J. Mater. Process. Technol. 177: 146-149

[61] Yao Z, Mei D, Tang P and Chen Z 2014 On the size effects in micro/meso semisolid extrusion-forging of A356 aluminum alloy. Int. J. Adv. Manuf. Technol. 73: $1243-1252$

[62] Yang M, Nakano S, Manabe K, Morikawa K, Ito K, Saito $\mathrm{H}$, Fuchigami K and Yokoi 2005 Fabrication of MEMS using micro metal forming process. In: Proceedings of the first ICNFT, pp. 135-140

[63] Adeosun S O, Sekunowo O I and Gbenebor O P 2014 Effect of die entry angle on extrusion responses of aluminum 6063 alloy. Int. J. Eng. Technol. 4(2): 127-134

[64] Lai X, Peng L, Hua P, Lan S and Ni J 2008 Material behavior modelling in micro/meso-scale forming process with considering size/scale effects. Comput. Mater. Sci. 43: 1003-1009

[65] Geiger M, Vollertsen F and Kals R 1996 Fundamentals on manufacturing of sheet metal microparts. Ann. CIRP 45(1): 277-282

[66] Vollertsen F 2008 Categories of size effects. Prod. Eng. Res. Dev. 2: 377-383

[67] Chan W L, Fu M W and Yang B 2011 Study of size effect in micro-extrusion process of pure copper. Mater. Des. 32: 3772-3782

[68] Yeh F H, Li C L and Lu Y H 2008 Study of thickness and grain size effects on material behavior in micro-forming. $J$. Mater. Process. Technol. 201: 237-241

[69] Furushima T, Tsunezaki H, Manabe K and Alexsandrov S 2014 Ductile fracture and free surface roughening behaviors of pure copper foils for micro/meso-scale forming. Int J. Mach. Tools Manuf. 76: 34-48

[70] Taureza M, Song X and Castagne S 2014 On the influence of workpiece material on friction in micro-forming and lubricant effectiveness. J. Mater. Process. Technol. 214(4): 998-1007

[71] Flitta I and Sheppard T 2003 Nature of friction in extrusion process and its effect on material flow. Mater. Sci. Technol. 19(7): 837-846

[72] Syahrullail S, Zubil B M, Azwadi C S N and Ridzuan M J M 2011 Experimental evaluation of palm oil as lubricant in cold forward extrusion process. Int. J. Mech. Sci. 53: 549-555

[73] Lazzarotto L, Dubar L, Dubois A, Ravassard P, Bricout J P and Oudin J 1998 A selection methodology for lubricating oil in cold metal forming processes. Wear 215: 1-9
[74] Zheng W, Wang G, Zhao G, Wei D and Jiang Z 2013 Modeling and analysis of dry friction in micro-forming of metals. Tribol. Int. 57: 202-209

[75] Piwnik J and Mogielnicki K 2010 The friction influence on stress in micro extrusion. Arch. Foundry Eng. 10: 451-454

[76] Pan W and Qin Y 2008 FE analysis of multi-cycle microforming through using closed-die upsetting models and forward extrusion models. Journal of Materials Processing Technology 201(1-3): 220-225

[77] Chan W L, Fu M W and Lu J 2011 The size effect on micro deformation behaviour in micro-scale plastic deformation. Mater. Des. 32: 198-206

[78] Geißdörfer S, Rosochowski A, Olejnik L, Engel U and Richert M 2008 Micro-extrusion of ultrafine grained copper. Int. J. Mater. Form. 1: 455-458

[79] Chan W L and Fu M W 2013 Meso-scaled progressive forming of bulk cylindrical and flanged parts using sheet metal. Mater. Des. 43: 249-257

[80] Piwnik J and Mogielnicki K 2010 Deformations in micro extrusion of metals. Arch. Foundry Eng. (Special Issue) 16(3): 87-90

[81] Ghassemali E, Tan M J, Jarfors A E W and Lim S C V 2013 Progressive micro-forming process: towards the mass production of micro-parts using sheet metal. Int. J. Adv. Manuf. Technol. 66: 611-621

[82] Fu M W and Chan W L 2013 Micro-scaled progressive forming of bulk micropart via directly using sheet metals. Mater. Des. 49: 774-783

[83] Ghassemali E, Arfors A E W, Tan M J and Lim S C L 2013 On the microstructure of micro-pins manufactured by a novel progressive micro-forming process. Int. J. Mater. Form. 6: 65-74

[84] Fu M W and Chan W L 2011 Geometry and grain size effects on the fracture behavior of sheet metal in microscale plastic deformation. Mater. Des. 32: 4738-4746

[85] Chan W L and Fu M W 2012 Experimental and simulation based study on micro-scaled sheet metal deformation behavior in microembossing process. Mater. Sci. Eng. A 556: 60-67

[86] Barbier C, Thibaud S, Richar F and Picart P 2009 Size effects on material behavior in micro-forming. Int. J. Mater. Form. 2(1): 625-628

[87] Yun W, Peilong D, Zhenying X, Hua Y and Jiangping W 2010 A constitutive model for thin sheet metal in microforming considering first order size effects. Mater. Des. 31(2): 1010-1014

[88] Fu M W, Yang B and Chan W L 2013 Experimental and simulation studies of micro blanking and deep drawing compound process using copper sheet. J. Mater. Process. Technol. 213(1): 101-110

[89] Deng J H, Fu M W and Chan W L 2011 Size effect on material surface deformation behavior in micro-forming process. Mater. Sci. Eng. A 528: 4799-4806

[90] Bai Y and Yang M 2013 Investigation on mechanism of metal foil surface finishing with vibration-assisted microforging. J. Mater. Process. Technol. 213(3): 330-336

[91] Wang S, Zhuang W, Balint D and Lin J 2009 A virtual crystal plasticity simulation tool for micro-forming. Procedia Eng. 1(1): 75-78 
[92] Rosochowska M, Rosochowski A and Olejnik L 2010 FE simulation of micro-extrusion of a conical pin. Int. J. Mater. Form. 3(1): 423-426

[93] Engel U and Eckstein R 2002 Micro-forming-from basic research to its realization. J. Mater. Process. Technol. 125-126: 35-44

[94] Fan Z 1995 The grain-size dependence of ductile fracture toughness of polycrystalline metals and alloys. Mater. Sci. Eng. A 191(1-2): 73-83

[95] Greenfield M A and Margolin H 1971 The interrelationship of fracture toughness and microstructure in a Ti-5.25Al$5.5 \mathrm{~V}-0.9 \mathrm{Fe}-0.5 \mathrm{Cu}$ alloy. Metall. Trans. 2(3): 841-847

[96] Rosenfeld A and Kak A 1982 Digital picture processing. Cambridge, MA: Academic Press, vol. 1, 435pp
[97] Levine M D 1985 Vision in man and machine. New York City, NY: McGraw-Hill

[98] Gao N, Wang C T, Wood R J K and Langdon T G 2012 Tribological properties of ultrafine-grained materials processed by severe plastic deformation. J. Mater. Sci. 47: 4779-4797

[99] Manjunatha L H and Dinesh P 2013 Hardness and wear properties of extruded MWCNT-reinforced with 6061Al metal matrix composites. Int. J. Sci. Eng. Res. 4(4): 974-990

[100] Soltani N, Nodooshan H R J, Bahrami A, Pech-Canul M I, Liu W and Wu G 2014 Effect of hot extrusion on wear properties of $\mathrm{Al}-15$ wt. $\% \mathrm{Mg} 2 \mathrm{Si}$ in-situ metal matrix composites. Mater. Des. 53: 774-781 